\section{$\sum \hat{z}$}

$\widehat{\nabla}$

t

\section{PHYSICAL MODEL STUDIES OF DISPERSION \\ IN FRACTURE SYSTEMS}

EGG-ELS--6845

DE85 011677

\author{
Apri1, 1985 \\ Laurence C. Hull \\ Geosciences Section \\ Earth and Life Sciences Branch \\ EG\&G Idaho, Inc.
}

\author{
Prepared for the \\ U.S. Department of Energy \\ Idaho Operation's office \\ Under DOE Contract No. DE-AC07-76I001570
}




\section{DISCLAIMER}

This report was prepared as an account of work sponsored by an agency of the United States Government. Neither the United States Government nor any agency Thereof, nor any of their employees, makes any warranty, express or implied, or assumes any legal liability or responsibility for the accuracy, completeness, or usefulness of any information, apparatus, product, or process disclosed, or represents that its use would not infringe privately owned rights. Reference herein to any specific commercial product, process, or service by trade name, trademark, manufacturer, or otherwise does not necessarily constitute or imply its endorsement, recommendation, or favoring by the United States Government or any agency thereof. The views and opinions of authors expressed herein do not necessarily state or reflect those of the United States Government or any agency thereof. 


\section{DISCLAIMER}

Portions of this document may be illegible in electronic image products. Images are produced from the best available original document. 


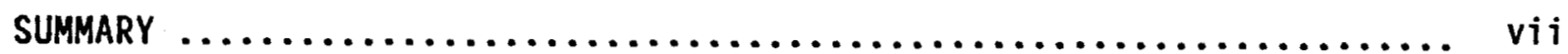

INTRODUCTION $\ldots \ldots \ldots \ldots \ldots \ldots \ldots \ldots \ldots \ldots \ldots \ldots \ldots \ldots \ldots \ldots \ldots \ldots \ldots \ldots \ldots$

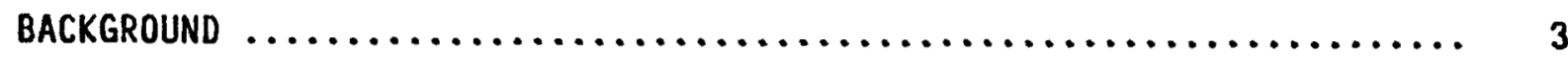

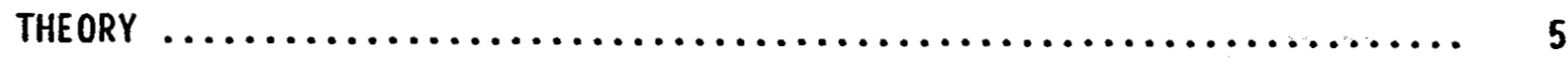

Parallel Plates..$\ldots \ldots \ldots \ldots \ldots \ldots \ldots \ldots \ldots \ldots \ldots \ldots \ldots \ldots \ldots \ldots$

Lognormal Distribution of Aperature $\ldots \ldots \ldots \ldots \ldots \ldots \ldots \ldots \ldots \ldots$

COMPUTER CODES USED FOR DATA ANALYSIS $\ldots \ldots \ldots \ldots \ldots \ldots \ldots \ldots \ldots \ldots \ldots \ldots$

Particle Tracking Algorithm ....................... 23

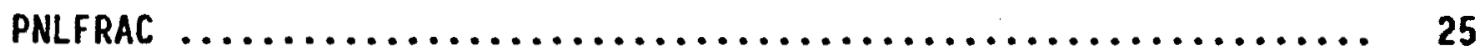

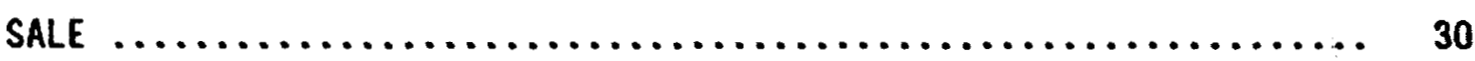

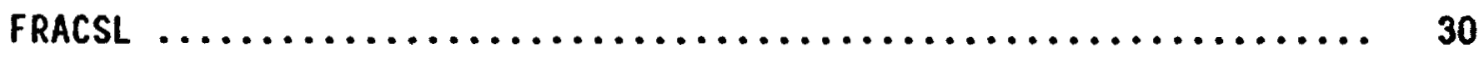

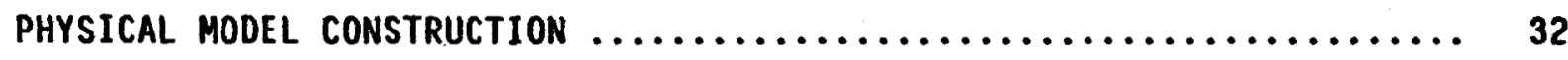

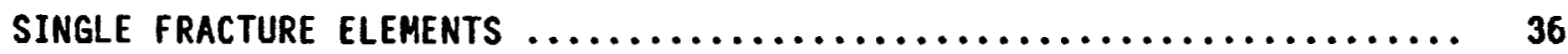

Single Fractures $\ldots \ldots \ldots \ldots \ldots \ldots \ldots \ldots \ldots \ldots \ldots \ldots \ldots \ldots \ldots \ldots \ldots \ldots$

Fracture Junction $\ldots \ldots \ldots \ldots \ldots \ldots \ldots \ldots \ldots \ldots \ldots \ldots \ldots \ldots \ldots \ldots$

INTERPRETATION OF INJECTION-BACKFLOW TRACER RECOVERY CURVES ........ 51

Raft River field Tests ............................ 51

Physical Model Description and Tests $\ldots \ldots \ldots \ldots \ldots \ldots \ldots \ldots \ldots$

Comparison of Resuits ........................... 55

DUAL-PERMEABILITY LABORATORY MODEL $\ldots \ldots \ldots \ldots \ldots \ldots \ldots \ldots \ldots \ldots \ldots$

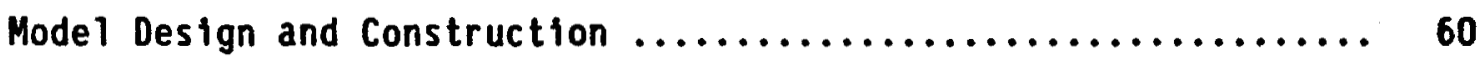

FRACSL SimuTations $\ldots \ldots \ldots \ldots \ldots \ldots \ldots \ldots \ldots \ldots \ldots \ldots \ldots \ldots \ldots \ldots$

CONCLUSIONS $\ldots \ldots \ldots \ldots \ldots \ldots \ldots \ldots \ldots \ldots \ldots \ldots \ldots \ldots \ldots \ldots \ldots \ldots \ldots \ldots \ldots$

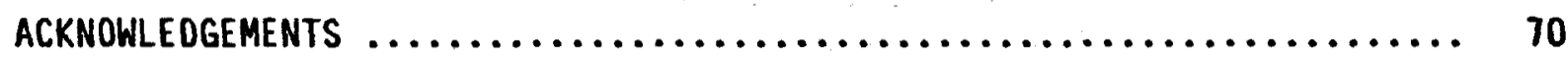

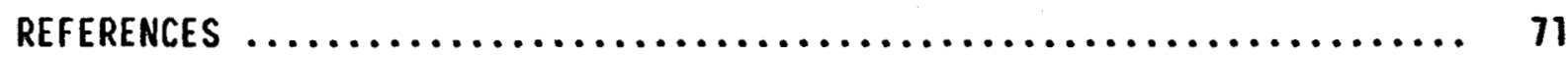




\section{FIGURES}

1. Illustration of the differences between in-situ and

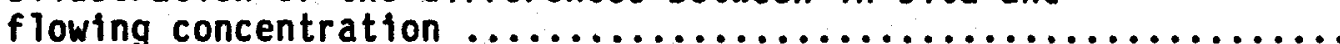

2. Dimensionless concentration versus dimensionless time for an electrode embedded in a fracture wall and for water exiting

3. Effect of Peclet number on the shape of tracer breakthrough

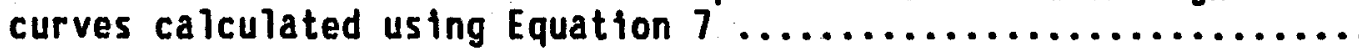

4. Dimensionless concentration profiles across a fracture having a constant concentration boundary at $\mathrm{y} / \mathrm{b}=0.0$.

5. Conceptual fracture model used to develop modified Poiseuille

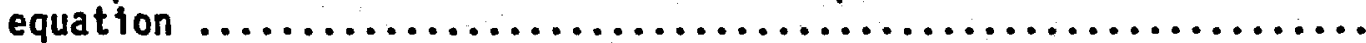

6. Effect of aperture variance on tracer breakthrough curves for fractures with lognormal distribution of aperture. ...........

7. Velocity profiles for 2-D parallel plates and for a 3-D channel with an aspect ratio of $6: 1 . \ldots \ldots \ldots \ldots \ldots \ldots \ldots \ldots \ldots$

8. Ratio of average fluid velocities in rectangular channels of various aspect ratios to average fluid velocity for

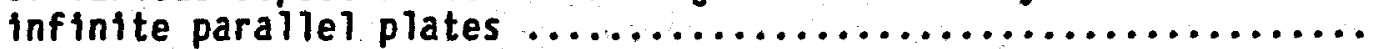

9. Normalized pseudo-three dimensional velocity profile for simulating rectangular channels with a $6: 1$ aspect ratio using a two-dimensional code

10. Normalized pseudo-three dimensional velocity profile for simulating rectangular channels with a $12: 1$ aspect ratio using a two-dimensional code

11. Normalized pseudo-three-dimensional velocity profile for simulating rectangular channels with a $50: 1$ aspect ratio using a two-dimensional code

12. Diagram showing installation of a specific conductance electrode

13. Experimental support equipment for physical model studies .......

14. Single fracture model for studying dispersion $\ldots \ldots \ldots \ldots \ldots \ldots \ldots$

15. Comparison of tracer breakthrough measured in the singlefracture laboratory model with PNLFRAC simulated breakthrough at an average flow velocity of $3.0 \mathrm{~cm} / \mathrm{min}$ 
16. Comparison of tracer breakthrough measured in the single-fracture laboratory modei with PNLFRAC simulated breakthrough at an average flow velocity of

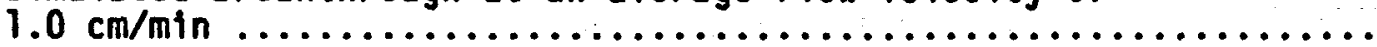

17. Comparison of tracer break-through measured in the single-fracture laboratory model with PNLFRAC simulated breakthrough at an average flow velocity of $0.3 \mathrm{~cm} / \mathrm{min}$

18. Comparison of tracer breakthrough measured in the single fracture laboratory model with PNLFRAC simulated breakthrough at an average flow velocity of $0.1 \mathrm{~cm} / \mathrm{min}$

19. Map of tracer concentration in a fracture where dispersion is controlled by the parabolic velocity

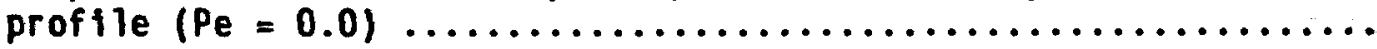

20. Comparison of analytical to numerical solutions for tracer breakthrough where dispersion is controlled by the parabolic velocity profile $(\mathrm{Pe}=0.0) \ldots \ldots \ldots \ldots \ldots \ldots \ldots$

21. Map of tracer concentration in a fracture where transverse molecular diffusion dominates development of a parabolic velocity profile $(\mathrm{Pe}=500) \ldots \ldots \ldots \ldots \ldots \ldots \ldots$

22. Comparison of analytical and numerical solutions for tracer breakthrough where transverse molecular diffusion dominates development of a parabolic velocity proftle $(\mathrm{Pe}=500)$

23. Map of tracer concentration in a fracture where both transverse molecular diffusion and the parabolic velocity profile affect tracer dispersion $(\mathrm{Pe}=5) \ldots \ldots \ldots \ldots$

24. Comparison of the analytical solution for transport at $\mathrm{Pe}=\mathrm{O}$ with a numerical simulation of velocity profile

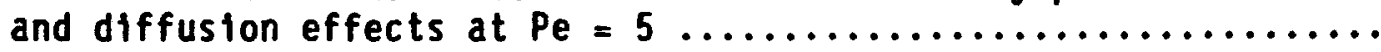

25. Comparison of a one-dimensional analytical solution that assumes transverse diffusion dominates development of the velocity profile with a numerical simulation of velocity proflle and diffusion effects at $\mathrm{Pe}=5$

26. Photograph of the laboratory fracture junction showing distribution of tracer when inflow from the left is 1.5 times inflow from the bottom.

27. Computer simulation of a fracture junction showing tracer distribution when inflow from the left is 1.5 times inflow from the bottom 
28. Computer simulation of a fracture junction showing distribution of tracer when inflow from the left equals inflow from the bottom. Average flow velocity is $7 \mathrm{~m} / \mathrm{day} . . . .$.

29. Maximum velocities in fractures of various apertures that permit sufficient residence time for mixing to occur due to molecular diffusion

30. Map showing locations of the Raft River geothermal field

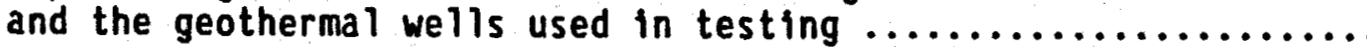

31. Tracer recovery curves for backflow portions of injection

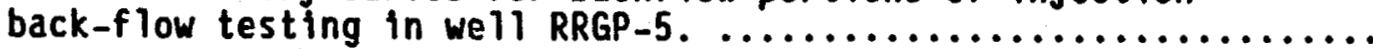

32. Tracy recovery curves for backflow portions of injection-

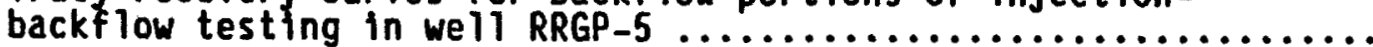

33. Fracture network used for variable volume injectionbackflow tests conducted in the laboratory

34. Tracer concentrations for injection-backflow tests conducted

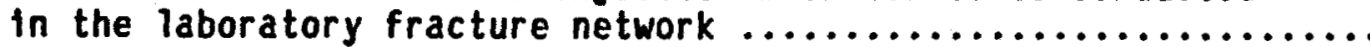

35. Tracer concentrations for injection-backflow tests conducted

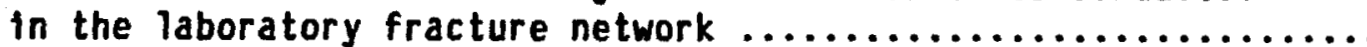

36. Changes in shape of a one-dimensional tracer front at various distances from an injection point based on classic dispersion theory

37. Changes in shape of a tracer front moving between infinite parallel plates at various distances from an injection point.

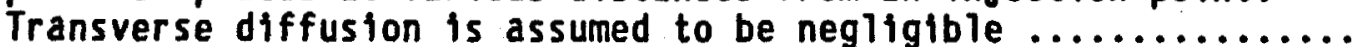

38. Schematic of the dual-permeability fracture network model

39. Plot of reduced tracer concentration versus the volume modifying function on probability paper lliustrating the method of determining the dispersion coefficlent from

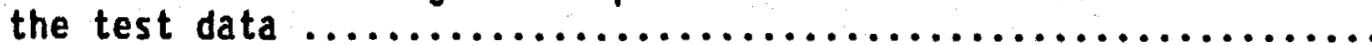

40. Predicted steady-state pressure distribution in the dualpermeability laboratory model using the FRACSL code

41. Predicted tracer distribution in the dual-permeability laboratory model using the FRACSL code 


\section{TABLES}

1. Normalized fluid velocities in rectangular channels with

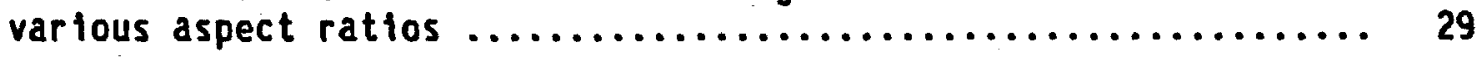

2. Coefficients of polynomial equations to describe the 2-0

projection of $3-D$ velocity profiles for rectangular channels .... 32 
The purposes of the laboratory-scale fracture network experiments are to study mechanisms controlling solute transport under conditions of known fracture parameters, to evaluate injection-backflow test procedures under conditions of known reservoir parameters, and to acquire data for validation of numerical models. Validation of computer codes against laboratory data collected under controlled conditions provides reassurance that the codes deal with important processes in a realistic manner.

The technology of building laboratory-scale physical models has advanced with succeeding generations of models. Early models used flow-through conductance cells to measure tracer concentrations at outlets from the mode1s. Incorporation of small $(3.2 \mathrm{~mm}$ diameter) platinum electrodes in the walls of the fractures permits measurement of tracer concentrations to be made throughout the models, without disturbing the flow field. Originally, the conductance electrodes were monitored one at a time using a specific conductance meter and a chart recorder. The data acquisition system has been computerized, and can now monitor up to 20 electrodes per test.

In working with single fracture models this year, it was found that the circular cross-section of stopcocks and tubing in the injection system was significantly affecting the shape of breakthrough curves. Special stopcocks have been designed and built that eliminate all tubing in the inlet system to the mode1. The stopcocks have rectangular channels with the same aspect ratio as the model being used, thus there is no change in geometry as fluid enters the model.

The most recent development in physical models is in the construction of a dual permeability fracture network. Matrix blocks, instead of being impermeable, will have porosity and permeability. Porous polyethylene has been selected as the porous material for model construction. It is readily available in large sheets $(1 \mathrm{~m}$ by $1 \mathrm{~m}$ by $2 \mathrm{~cm}$ ), is easy to machine, and has reasonable hydraulic properties (porosity $35 \%$; permeability $0.20 \mathrm{~cm} / \mathrm{min}$ ). 
Because it is easy to machine, a rather elaborate fracture network has been designed. The model is currently under construction, and will be ready for testing during FY $\mathbf{- 8 5}$.

Preliminary simulations of the dual-permeability physical model have been made using the FRACSL reservoir code. These simulations permit locating electrodes and piezometers in the most advantageous positions to record tracer migration and pressure response. Simulations are also invaluable in helping to plan the test program that will be used.

Much of the physical modeling effort this year was oriented towards validating the particle tracking algorithm used in FRACSL, and developing a better theoretical understanding of transport processes in fractures. The former activity has shown that particle tracking has many advantages over numerical methods for simulating solute transport. The latter activity has provided important insight into how to design future testing of fracture systems.

Experiments were conducted in single fractures and single fracture junctions, and data on tracer migration collected. The Prickett, Naymik. and Lonnquist Random Walk aquifer simulation program has been modified to simulate flow in single fractures. Both infinite parallel plates and rectangular channels can be simulated. The ability to handle rectangular channels is necessary for simulating laboratory models, which are rectangular channels with finite aspect ratios. Computer simulations were quite successful in matching the laboratory results with no manipulation of parameters. Flow is based on the three-dimensional velocity profile for rectangular channels. A diffusion coefficient for the potassium chloride tracer of $1.2 \times 10^{-3} \mathrm{~cm}^{2} /$ min was taken from the 11 terature.

The particle tracking algorithm was also used to simulate infinite parallel plates under conditions where analytical solutions to the transport equation could be derived. The first case is for zero diffusion in the fracture, and transport based on a parabolic velocity profile. The second case is for diffusion homogenizing the tracer solution across the fracture. The particle tracking algorithm matched both analytical 
solutions quite well, with the same grid for both simulations. Most numerical techniques for solving the transport equation for this broad range of flow conditions would have required extensive changes to the model grid.

To expand our abilities to simulate increasingly more complex laboratory models, a method of adapting FRACSL, a two-dimensional code, to simulating the three-dimensional laboratory fracture models was necessary. This has been done by projecting the three-dimensional velocity profile for rectangular channels into two-dimensions. Third order polynomial equations are used for the new velocity profile. Diffusion coefficients must be scaled to account for the decreased distance particles must move in two-dimenstons. So far this has been done by brute force matching of computer simulations, but theoretical approaches are being evaluated. FRACSL can be readily modified to accept the polynomial equations instead of the usual parabolic velocity profile.

From the single fracture studies and from theoretical considerations, it has been found that diffusion will homogenize tracer concentration across a fracture in a dimensionles.s time of:

$\frac{D_{m} t}{b^{2}}=2.0$

The appearance of tracer recovery curves from injection-backflow field tests should change dramatically as reduced times increase from less than 2 to greater than 2. Thus, by planning the lengths of injection-backflow tests to span this critical time interval, estimates of fracture apertures may be possible.

This past year our ablitty to simulate fractures and fracture systems has been greatly expanded. The particle tracking algorithm has been verifled against laboratory data and analytical solutions. Model construction techniques have been refined, with many problems that introduced uncertainties in measurements being eliminated. Once a good 
sealing material has been found for the porous polyethylene, laboratory experiments will be conducted on the dual-permeability fracture network. A better theoretical understanding of transport in fractures will permit the design of more sensitive field tests for measuring reservoir parameters. 


\section{PHYSICAL MODEL STUDIES OF DISPERSION}

IN FRACTURE SYSTEMS

\section{INTRODUCTION}

Geothermal energy applications frequently require large quantities of hydrothermal fluids. Injection of these spent geotherma' fluids may be the only economically feasible and environmentally suitable means for disposal. Injection may also maintain reservoir pressures and prevent surface subsidence. However, the effects of injection may not always be beneficial to reservoir performance. For example, breakthrough of cooled injected fluids has lowered the enthalpy of production fluids at onikobe and Otake geothermal fields in Japan (Horne, 1982). Multiwell tracer tests at Wairakei show transit of injected fiuids between wells can take as 1ittle as five to ten days (Fossum and Horne, 1982). To properly assess the effects of injection on geothermal systems, a better understanding of the nature of fractures in geothermal reservoirs is required. Tracer tests can provide the researcher with an increased understanding of the fluid travel paths and rates of movement through fractured reservoirs. However, the interpretation of tracer tests in fractured reservotrs is not based on a sound theoretical understanding of the processes that control tracer behavior in fractures.

The Department of Energy (DOE) has recognized the need for additional research into the complex subsurface behavior of geothermal reservoirs during injection. A comprehensive research program has been estabitished to examine the problems associated with the injection of spent geothermal fluids into fractured reservoirs (Downs et a).,1982; Capuano et al., 1983). The purpose of the DOE injection program is to develop new methods for reservoir assessment that can be used in fractured geothermal reservoirs. EG\&G Idaho and the Earth Sciences Laboratory of the University of Utah Research Institute (UURI), under the DOE Idaho Operations Office, have been actively involved in this injection research program. The joint effort consists of a series of field experiments with supporting laboratory and theoretical work. 
The purposes of laboratory scale experiments are to study mechanisms of solute transport under controlled conditions of aperture, roughness, flow, geometry, and matrix permeability, and to obtain data for validation of computer codes. Field testing is designed to evaluate new methods of reservoir assessment, and to obtain data on tracer behavior in geothermal reservoirs. In conjunction with the field and laboratory testing. numerical simulation methods are being developed for analysis of tracer movement in fracture systems with matrix porosity and permeability (Miller, 1983; Clemo and Miller, 1984). Validation of these computer codes against laboratory data collected under controlled conditions provides reassurance that the codes deal with the important processes in a realistic manner.

This paper summarizes the laboratory physical modeling that has been conducted by EG\&G Idaho, and provides a discussion of test results from the laboratory that have bearing on the interpretation of field tests conducted in the fractured reservoir at Raft River, Idaho. A discussion of the approaches to dealing with solute transport in fractures is given first. and the particle tracking algorithm, used in the computer codes being developed by EG\&G, is presented and validated. 
A large number of studies have been published in the past 10-12 years dealing with solute transport in fractured media. The vast majority of this work deals with solute transport in single fractures. Much of this work has been motivated by the need for a repository for storage of nuclear wastes that is safely sequestered from man and the environment.

Many of the papers deal with a dual porosity aquifer, where fractures occur in a rock that also contains primary porosity. Usually, the permeability of the matrix blocks is considered insignificant relative to the permeability of the fracture system. The matrix blocks do not participate in fluid flow through the rock. but can be involved in heat transfer and solute retardation phenomena. Diffusion from the fracture into the rock matrix retards the migration of solutes. None of the approaches deals with advective transport between fracture and matrix. Solute transport in the fracture is elther by advection alone (McKinley and West, 1982; Rundberg et a1.. 1981) or by advection and dispersion based on a one-dimensional solution to the advection-dispersion equation (Nuttall and Ray, 1981; Tang et a1., 1981; Travis and Nutta11, 1982). Computer codes that can simulate complex fracture networks, and which use this approach have been presented by Baca et a1., (1981), Huyakorn (1982), and Travis (1984).

Alternative methods for dealing with dispersion in fractured rocks have been proposed. Krizek et a1., (1972) developed a numertcal model for solute transport in a fractured network. In their model, dispersion was a direct result of the velocity proflle of fluid moving through the individual fractures. Grisak and Pickens (1980) used an approach that combined both the velocity profile concept and a one-dimensional solution to the advection-dispersion equation. They divided the fracture into six zones, calculated the mean velocity in each zone based on the velocity profile, and then calculated dispersion based on the advection-dispersion equation for each zone. Horne and Rodriguez (1981) and Fossum and Horne 
(1982) use a one-dimensional solution to the classic advection-dispersion equation, but with a dispersion coefficient that is related to fracture aperture.

Neretnieks and coworkers (Neretnieks, 1979, 1981, 1983; Abelin et a1., 1982; Neretnieks et a1., 1982) have taken the approach that channeling within a fracture produces dispersion. Their model is based on an idealization of a fracture as a set of parallel channels of differing width. The population of channel apertures has a lognormal frequency distribution, and each channel has a velocity proportional to the square of the aperture. Solute breakthrough measurements are made on mixtures of water from all channels, thus producing a gradual breakthrough of tracer. This conceptual model was applied to breakthrough curves measured on a laboratory fracture in granite.

Complete mixing at fracture junctions has been found or assumed in several studies of fracture networks. Krisak et a1.. (1972) carried out experiments on single fracture junctions to validate their numerical model, and found results suggesting complete mixing of tracers at fracture junctions. Thefr experiments were 1 imited to cases where tracer entered the junction from a single fracture and left via two or three that were at equal potent1a7s. Schwartz et a1., (1982, 1983) adopted this concept for a stochastic numerical modeling study of solute migration through discontinuous fracture networks. Experimental studies conducted by Wilson and Witherspoon (1976) and Hull and Koslow (1982) found no evidence of complete mixing at fracture junctions where flow converged from two fractures and left via two fractures. 


\section{THEORY}

Most approaches to dispersion in fractures are based on parallel plate theory. Dispersion is related to the parabolic velocity profile that develops due to friction against fracture walls. This is the most commoniy used approach, and the one that has been adopted for current modeling studies, both numerical and in the laboratory. A second approach to dispersion in fractures has been presented by Neretnieks et a1., (1982, 1983). This approach is based on natural fractures where apertures are not constant. Following Snow (1970), Neretnieks postulates a lognormal distribution of fracture apertures. Because velocity is proportional to aperture squared, the tracer front will be dispersed because of the different paths. In this section, the equations governing dispersion for these different approaches will be presented, analytical solutions derived, and implications of the approaches discussed.

\section{Parallel Plates}

When dealing with tracer concentration, in either fractures or porous media, there are two different concentrations that are of interest; in-situ concentration and flowing concentration. In-situ concentration is the spatially averaged concentration at a specific cross-section within a fracture (Figure 1a). It is the concentration that would be measured with an electrode embedded in the fracture wall. Flowing concentration is the volumetrically averaged concentration of fluid passing through a plane across the fracture (Figure $1 b$ ). It is the concentration that would be measured by collecting a water sample over some small time increment. Equations describing the two types of concentration are:

$$
\begin{aligned}
& C=C_{0} \frac{\int_{0}^{y^{*}} A(y) d y}{A_{t}} \quad \text { (in-situ) } \\
& C=C_{0} \frac{\int_{0}^{y^{*} v(y) A(y) d y}}{u A_{t}} \quad \text { (flowing) }
\end{aligned}
$$




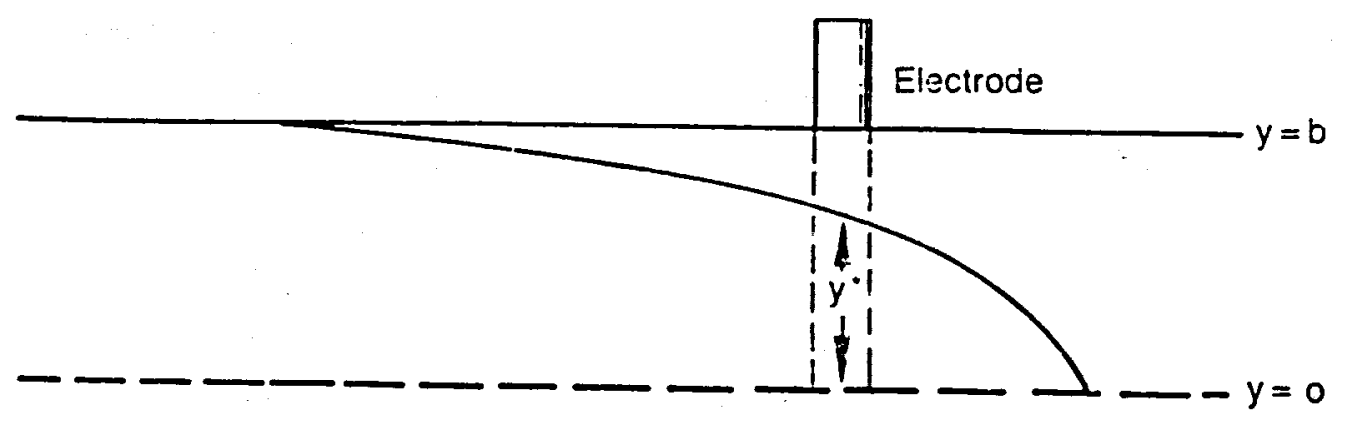

a. In-situ concentration

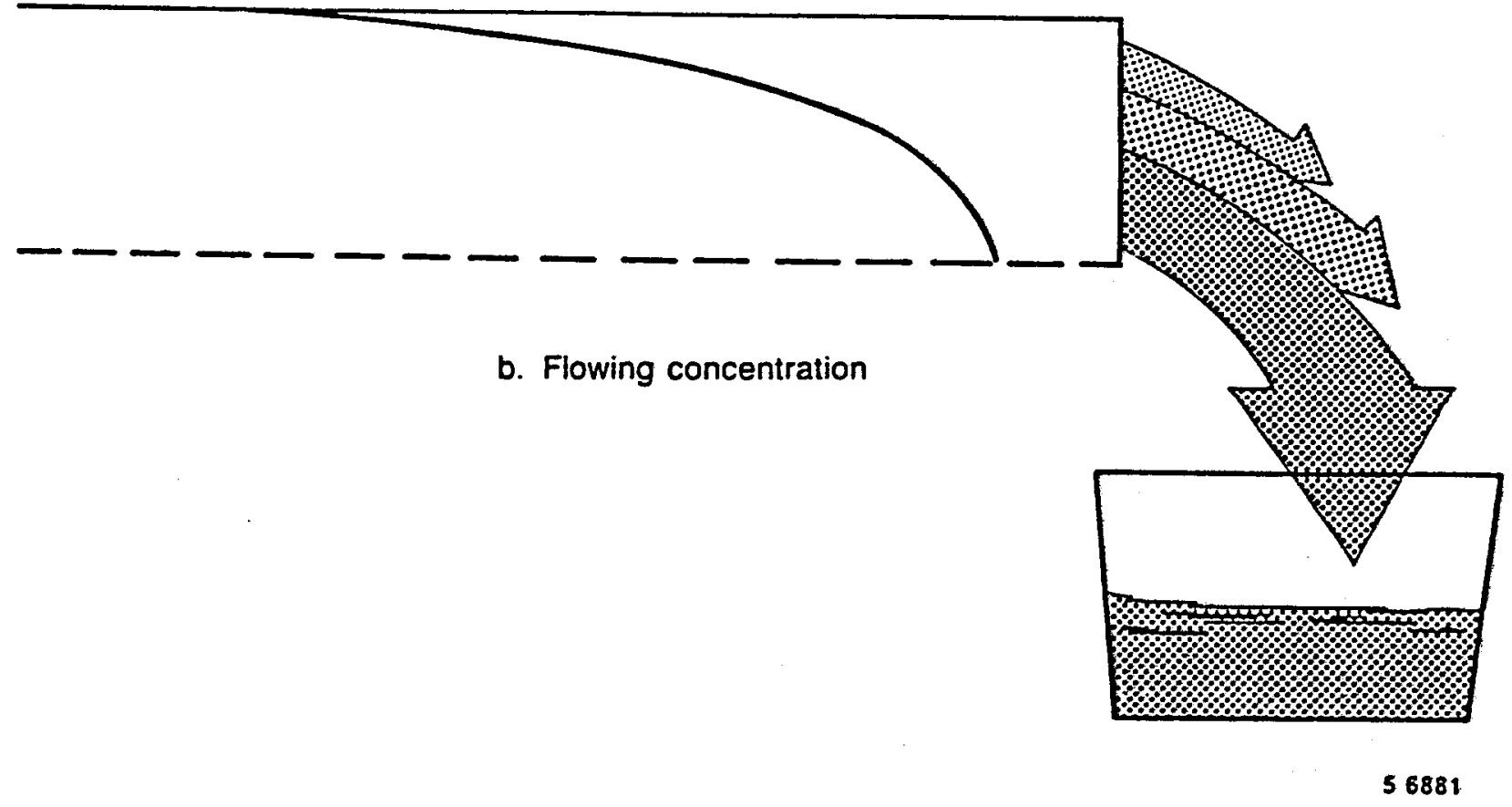

Figures $1 \mathrm{a}$ and 1b. Illustration of the differences between in-situ and flowing concentration. 
where

$C=$ tracer concentration

$C_{0}=$ injected tracer concentration

$v(y)=$ fluid velocity at a distance $y$ from the centerline of the fracture

$u=$ average linear fluid velocity

$A(y)=$ incremental area

$A_{t}=$ total cross-section of fracture

$y=$ transverse position in fracture, measured from the center ine

$y^{\star}=$ transverse position of interface between tracer solution and native fluid (see Figure $1 \mathrm{a}$ and $1 \mathrm{~b}$ ).

The value of $y^{\star}$ can be defined by using the Poiseuille equation for the velocity profile between parallel plates (Albertson et al., 1960):

$v(y)=\frac{3 u}{2}\left(1-y^{2} / b^{2}\right)$

Rearranging and solving for y gives:

$y^{\star}=b\left(1-\frac{2 x}{3 u t}\right)^{1 / 2}$ 
where

b = half the fracture aperture

$x=$ distance coordinate along the fracture

$t=$ residence time in fracture.

$A(y)$ in Equations $1 a$ and $1 b$ can be replaced by $2 d y$ and $A_{t}$ by $z b$ where $z$ is the height of the fracture normal to flow. However, as this height drops out of all equations, it does not affect the results as long as it is very large relative to aperture $(z>100 \mathrm{~b})$. Because of symmetry about the centerline of the fracture, the integration needs to extend over only half the fracture aperture.

Integrating Equation la across half the with of the fracture and evaluating the result at $y^{*}$ gives the equation for in-situ tracer concentration where concentration is controlled only by the parabolic velocity profile within the fracture.

$c=c_{0}\left(1-\frac{2 x}{3 u t}\right)^{1 / 2}$

For flowing concentration, the point velocity is defined using Equation 2. and Equation $1 \mathrm{~b}$ is integrated across half the width of the fracture. The result is evaluated at $y^{\star}$ giving the equation for flowing concentration in a fracture.

$C=\frac{c_{0}}{2}\left(4-3\left(\frac{2 x}{3 u t}\right)^{2}-\left(\frac{2 x}{3 u t}\right)^{3}\right)^{1 / 2}$

Plotting reduced concentration $\left(C / C_{0}\right)$ versus reduced time $(u t / x)$, shows the difference between Equations 4 and 5 (Figure 2). The difference between the two curves is the difference between measuring tracer concentration in-situ, and collecting samples for measurement. The flowing concentration curve describes the transfer of tracer from one fracture to 


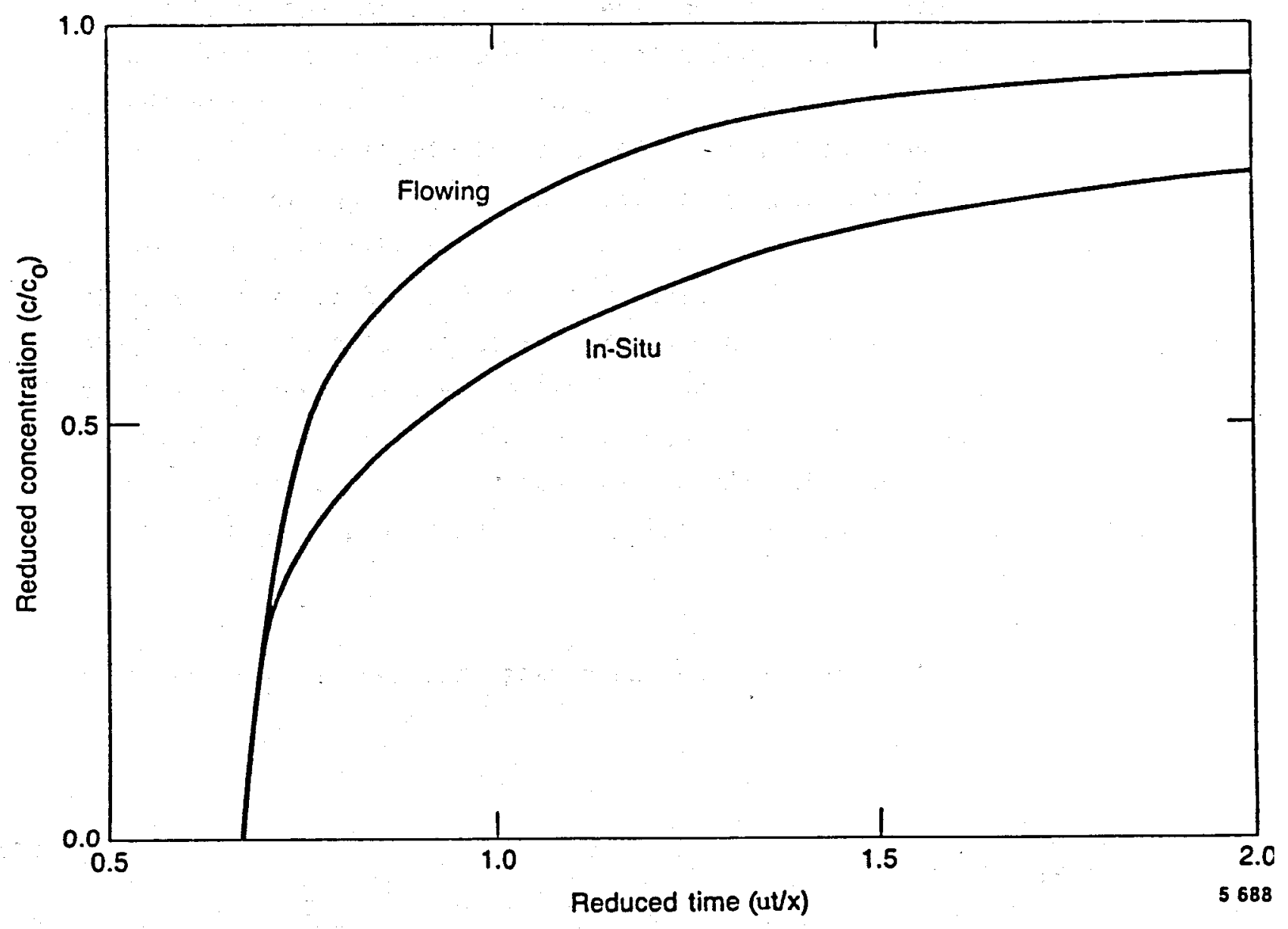

Figure 2. Dimensionless concentration versus dimensionless time for an electrode embedded in a fracture wall (Equation 4, in-situ) and for water exiting a fracture at a fracture junction or we1l (Equation 5, flowing). 
another across a fracture junction, or from a fracture into a wellbore. The flowing concentration curve $r$ ises more steeply because it is weighted by flow volume. As a result, the more rapidiy moving fluid down the center of the fracture, which carries more tracer, is weighted more heavily than the slower moving fluid along the fracture walls. For the in-situ concentration, all portions of the fracture are weighted equally.

Transverse diffusion between streamilines in a fracture will move tracer from the fast-moving water in the center of the fracture into slower-moving water nearer the fracture walls. This will reduce the rate of movement of tracer relative to the water flowing along the center of the fracture. At very low flow rates, this transverse diffusion will homogenize tracer in the fracture. Under these conditions, the velocity of a solute particle exiting a fracture will be independent of the velocity of the solute particle when it entered the fracture. Each solute particle will have sampled a range of transport velocities, and there will be no correlation between input and output velocities of particles. Transport can then be described using the one-dimensional advection-dispersion equation, and the tracer front will move at the average ilnear velocity of fluid in the fracture.

The differential form of the one-dimensional advection-dispersion equation is:

$$
\frac{\partial C}{\partial t}=D_{l} \frac{\partial^{2} C}{\partial x^{2}}-u \frac{\partial C}{\partial x}
$$

Ogata and Banks (1961) derived an analytical solution in one-dimension for constant concentration boundary conditions and a step input:

$$
\frac{C}{C_{0}}=\frac{1}{2}\left[\operatorname{erfc}\left(\frac{1-\tau}{2 \sqrt{\tau / P e}}\right)+e^{P e} \operatorname{erfc}\left(\frac{1+\tau}{2 \sqrt{\tau / P e}}\right)\right]
$$


where

$$
\begin{aligned}
& \text { erfc }=\text { complementary error function } \\
& \mathrm{Pe}=\text { Peclet number } u \times / D_{\ell} \\
& D_{\ell}=\text { Iongitudinal dispersion coefficient } \\
& \tau \quad=\text { dimensioniess time, ut/x. }
\end{aligned}
$$

The parameter that controls the shape of breakthrough curves described by Equation 7 is the Peclet number. When the Peclet number is large (> 200), a symmetrical, sigmoidal shaped curve is produced (Figure 3 ). When the Peclet number is smal1, the curve is asymmetrical, and in the extreme $(\mathrm{Pe}<1)$, appears almost exponential.

Treatments of dispersion in single fractures that use the one-dimensional advection-dispersion equation frequently treat the dispersion coefficient as independent of fracture aperture and a linear function of fluid velocity (Nuttall and Ray, 1981; Noorishad and Mehran, 1982). For parallel plate theory, however, the dispersion coefficient should be a function of aperture, and be related to velocity squared. Taylor (1953, 1954) derived an expression for the dispersion coefficient for a solute flowing through a circular tube. A similar derivation can be made for a fracture by changing the geometry from circular to parallel plates (Horne and Rodriguez, 1981).

Based on parallel plate theory, as water moves along a fracture, the water moving along the center of the fracture will move at a rate equal to 1.5 times the mean velocity. This generates a very steep concentration gradient transverse to the direction of flow. This approach to transport in fractures is two-dimensional, with both longitudinal and transverse motion explicitly considered. Molecular diffusion will cause some of the tracer to migrate from the faster water, moving down the center of the fracture, into the slower water moving along the fracture walls. At slow 


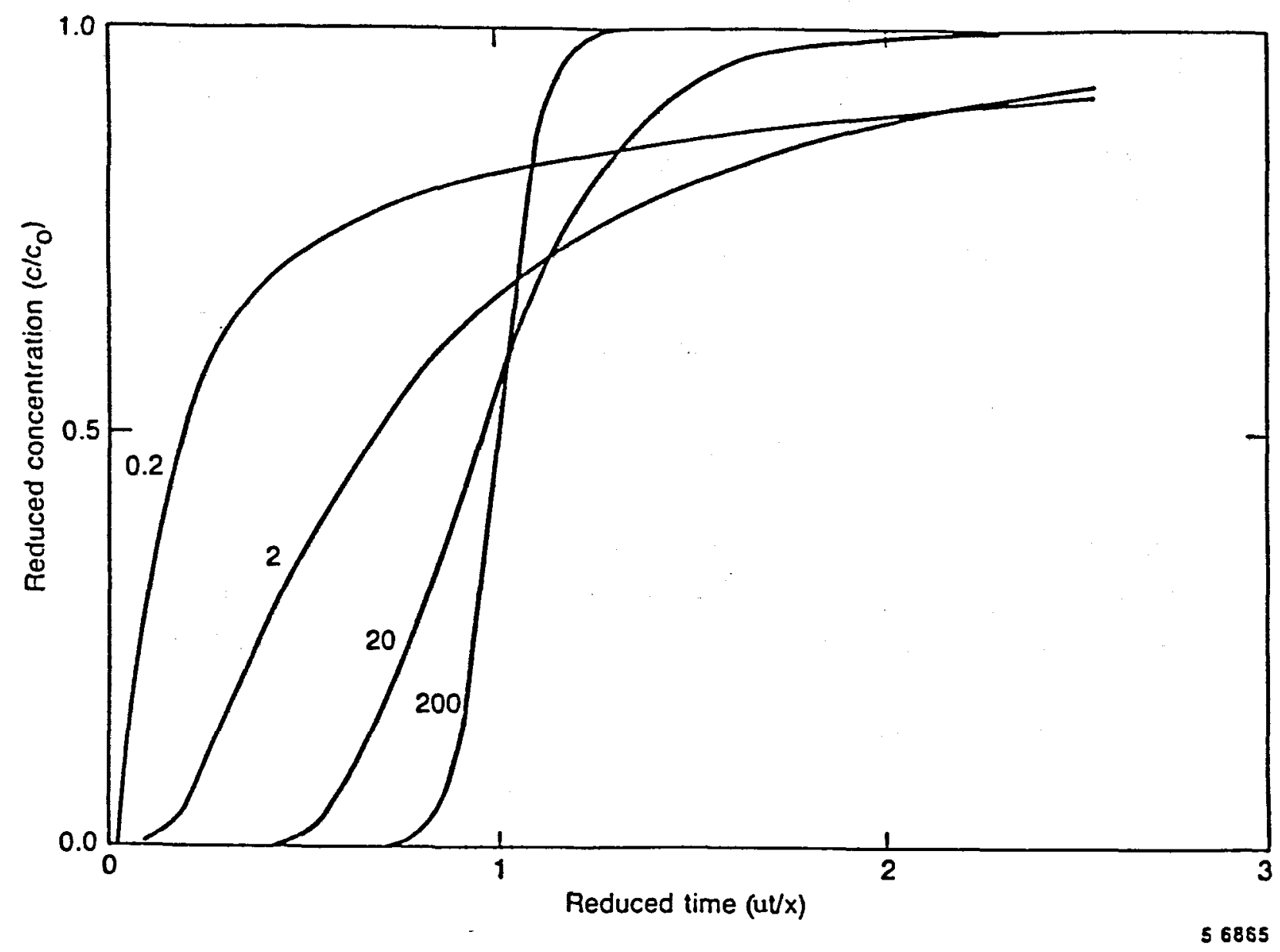

Figure 3. Effect of Peclet number on the shape of tracer breakthrough curves calculated using Equation 7.

flow rates, diffusion will result in homogenization of the tracer front across the fracture. The change in concentration at a point within the fracture will be determined by the combined effects of diffusion and advection. The two-dimensional differential equation that describes this process is:

$\frac{\partial C}{\partial t}=D_{m}\left(\frac{\partial^{2} C}{\partial x^{2}}+\frac{\partial^{2} c}{\partial y^{2}}\right)-\frac{3 u}{2}\left(1-\frac{y^{2}}{b^{2}}\right) \frac{\partial C}{\partial x}$

where $D_{m}$ is the coefficient of molecular diffusion. As long as the walls of the fracture are impermeable, there will be no advection perpendicular 
to the fracture. This is not the case for dual porosity situations, where matrix permeability is present.

It can generally be assumed that advective transport along the fracture (x direction) will dominate diffusive transport in that direction. Therefore, only transverse diffusion need be considered. Equation 8 can be transformed to a coordinate system that moves at the average velocity of the tracer front by making the following substitutions:

$\rho=y / b$

$\xi=x-u t$

$\frac{d x}{d t}=v(y)$

Substituting Equations 9 through 11 in Equation 8 gives the two-dimensional equation for transport through a fracture in terms of a relative coordinate system.

$\frac{\partial C}{\partial t}=\frac{D_{m} \partial^{2} C}{b^{2} d \rho^{2}}-\frac{3 u}{2}\left(\frac{1}{3}-\rho^{2}\right) \frac{\partial C}{\partial \xi}$

A solution to Equation 12 can be obtained for conditions where transverse diffusion is rapid relative to the development of a transverse concentration gradient due to longitudinal transport. For steady state conditions in the moving coordinate system, $\partial C / \partial t=0$ and $\partial C / \partial \xi$ can be assumed constant. Carrying out the double integration on $\rho$ gives the tracer concentration as a function of lateral position and input tracer concentration.

$C=C_{0}+\frac{u b^{2} \partial C}{4 D_{m} \partial \xi}\left(\rho^{2}-\frac{1}{2} \rho^{4}\right)$ 
To determine the average tracer concentration $(\vec{c})$ over the width of the fracture, Equation 13 must be integrated from $\rho=0$ to $\rho=1$.

Back substituting the result of this integration into Equation 13 gives the point concentration as function of the average tracer concentration.

$C=\bar{C}+\frac{u b^{2} \partial C}{4 D_{m} \partial \xi}\left(-\frac{7}{30}+\rho^{2}-\frac{1}{2} \rho^{4}\right)$

The flux of tracer along the fracture ( $J)$ is given by:

$J=\int_{0}^{1} \bar{C} v(\rho) d \rho$

Integrating Equation 15 using Equation 14 for the average tracer concentration and the parabolic velocity profile (Equation 2 with substitution of Equation 9 ) to describe the velocity as a function of lateral position gives:

$J=-\frac{2 u^{2} b^{2}}{105 D_{m}} \frac{\partial C}{\partial \xi}$

where

$$
D_{l}=\frac{2 u^{2} b^{2}}{105 D_{m}}
$$

defines the longitudinal dispersion coefficient. The dispersion coefficient is related to both fracture aperture and velocity squared. Replacing Equation 17 in the definition for the Peclet number, see Equation 7, gives the Peclet number for fractures:

$$
P_{f}=\frac{105 D_{m} x}{2 u b^{2}}
$$


Equation 17 substituted in Equation 7 will be valid for fractures only under certain conditions. To evaluate these conditions, the processes involved must be considered. The general assumption in the derivation was that transverse diffusion would homogenize the tracer across the fracture before fluid reached the end of the fracture. The time required for diffusion to homogenize the tracer can be calculated from an analytical solution to the diffusion equation presented by Crank (1975). The boundary conditions for this solution are a constant concentration at the centerline of the fracture and $d c / d y=0$ at the fracture wall. The constant concentration boundary condition is used because as diffusion moves tracer from the center of the fracture, new tracer will be brought into place by the more rapidly moving water in the center of the fracture. The one-dimensional solution will only be valid when the tracer concentration averaged across the fracture is equal to the input concentration everywere behind the moving front. The less rigorous boundary condition of constant mass for the diffusion equation only provides that point concentrations across the fracture equal the average concentration at that point, i.e. that the tracer is homogenized. This is not sufficient since it allows for a tracer concentration gradient in the longitudinal direction along the fracture which stretchs from the origin of the fracture to the moving front. The equation describing diffusion under the constant concentration boundary conditions is (Crank, 1975):

$$
\begin{aligned}
c / c_{0}= & \sum_{n=0}^{\infty}(-1)^{n} \operatorname{erfc}\left(\frac{(2 n+1)-y / b}{2 \sqrt{D_{m} t / b^{2}}}\right) \\
& +\sum_{n=0}^{\infty}(-1)^{n} \operatorname{erfc}\left(\frac{(2 n+1)+y / b}{2 \sqrt{D_{m} t / b^{2}}}\right)
\end{aligned}
$$

A plot of dimensionless concentration versus dimensionless time is shown in Figure 4. Tracer will have homogenized in a dimensionless time of:

$$
\frac{D_{m} t}{b^{2}}=2.0
$$




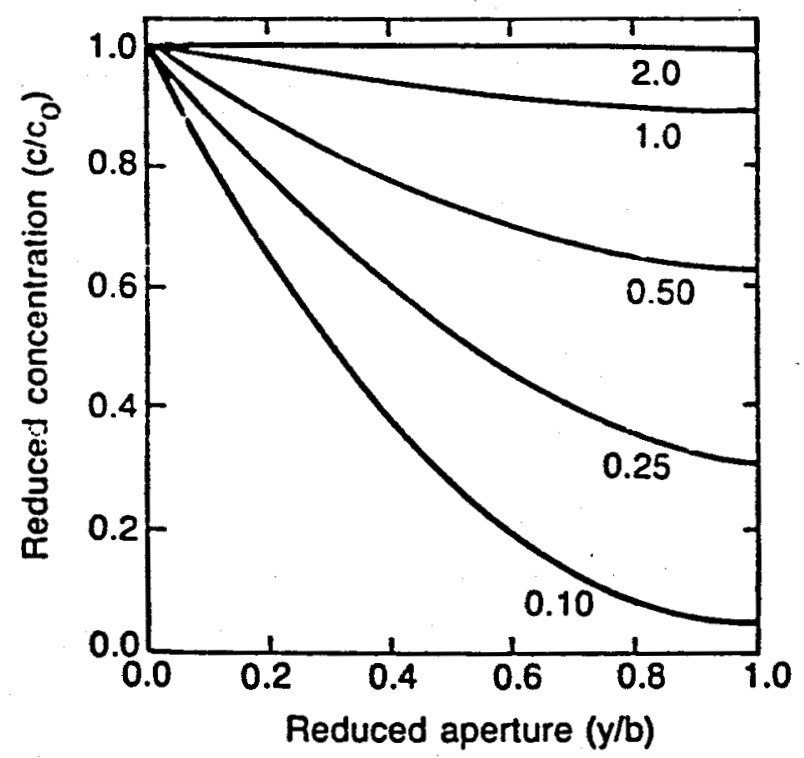

56861

Figure 4. Dimensionless concentration profiles across a fracture having a constant concentration boundary at $y / b=0.0$. Curves were calculated using Equation 19 for the various dimensionless times shown.

The tracer moving along the center of the fracture will arrive at the end of the fracture in a dimensionless time of:

$\frac{u t}{x}=0.67$

Solving Equations 20 and 21 for time and requiring that the transport time be greater than the diffusion time gives:

$\frac{2 b^{2}}{D_{m}}<\frac{0.67 x}{u}$

or rearranging:

$\frac{D_{m} x}{u b^{2}}>3.0$ 
Multiplying both sides of Equation 23 by $105 / 2$ gives the Peclet number for fractures (compare to Equation 18). This ratio must therefore be greater than 157.5 to apply Equation 7 using Equation 17 for the dispersion coefficient. Comparison between this limiting Peclet number and shapes of breakthrough curves plotted in Figure 3 shows that breakthrough curves for fractures under the assumption of one-dimensional dispersion will always be symmetrical and sigmoidal.

One aspect of this definition of a Peclet number for fractures is that the Peclet number is inversely related to fluid velocity. For the classic Peclet number, the magnitude of the ratio increases as velocity increases. For the fracture Peclet number, the magnitude decreases as velocity increases. Therefore, the one-dimensional approach is only applicable at low flow rates where diffusion can produce homogenization. When the limiting Peclet number requirement is violated, the assumptions behind the derivation of Equation 17 are violated, and a two-dimensional approach to dispersion is required. Application of Equation 7 to fractures at low Peclet numbers is not valid. Hydrodynamic constraints on peak velocities under the parallel plate assumption are violated by application of Equation 8 if the Peclet number is Tess than 157.5 .

\section{Lognorma 1 Distribution of Aperture}

The velocity profile approach to dispersion in fractures treats fractures as two-dimensional. Fractures have a third-dimension, height. Also, fracture surfaces are not smooth parallel plates, but are rough with asperities and sections that may be closed. Neuzil and Tracy (1981) conceptualized a fracture as a series of finite parallel plates. with apertures that were lognormally distributed (Figure 5). Aperture requires two parameters to describe, mean and variance. Neretnieks and coworkers (1982, 1983) expanded on this concept to show how this lognormal distribution of aperture would affect solute transport.

A fracture is conceptualized as a series of smaller parallel plates. where the aperture of the parallel plates varies over a range, and can be described by a probability density function. The steps between plates are 


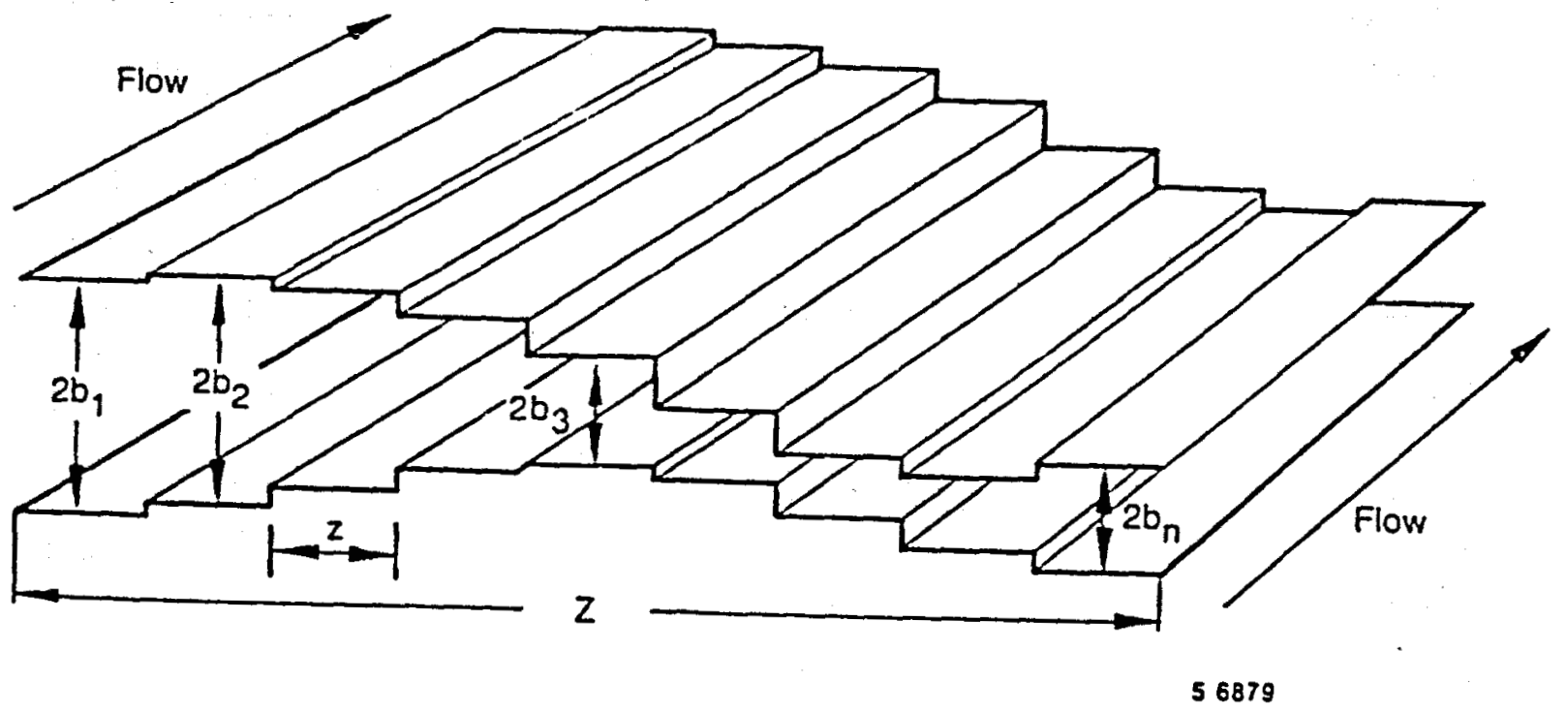

Figure 5. Conceptual fracture model used to develop modified Poiseuille equation (from Neuzil and Tracy, 1981).

assumed to have no effect on the flow. The concentration of tracer exiting the fracture at any given time is dependent on the ratio of discharge that is carrying tracer to total discharge from all channels. This ratio is given by:

$\frac{C}{C_{0}}=\frac{Q^{*}}{Q_{t}}=\frac{\int_{b^{*}}^{\infty} v(b) A(b) f(b) d b}{\int_{0}^{\infty} v(b) A(b) f(b) d b}$

where $Q^{*}$ is the volumetric flow rate carrying tracer and $Q^{t}$ is the total volumetric flow rate. The limit of integration $b^{*}$, is the smallest aperture that carries tracer after a time $t^{*}$, where $t^{*}$ is related to the length of the fracture divided by the velocity in the particular fracture element $\left(x / u^{*}\right)$. Snow (1970) found that fracture apertures in granitic rocks could be described by a lognormal probability density function.

The functional relations between velocity, area, and aperture are given by:

$v(b)=\frac{r b^{2} d h}{3 \mu d x}$ 
$f(b)=\frac{1}{b 2 \pi \sigma^{2}} \exp \frac{-(\ln b-m u)^{2}}{2 \sigma^{2}}$

where

$$
\begin{aligned}
\gamma & =\text { specific gravity } \\
\mu & =\text { dynamic viscosity } \\
m u & =\text { mean of the aperture } \\
\sigma^{2} & =\text { variance of the aperture }
\end{aligned}
$$

To make the equations equivalent to those discussed in the previous section, an average velocity must be determined. This can then be substituted into Equation 25 for $v(b)$ in order to eliminate the gradient term. Velocity is the discharge divided by the area, and is given by the equation:

$u=\frac{Q}{A}=\frac{\int_{0}^{\infty} v(b) A(b) f(b) d b}{\int_{0}^{\infty} A(b) f(b) d b}$

Using Equations 26 and 27 to describe the functional relation between area and aperature gives the equation for area of the fracture:

$A=\int_{0}^{\infty} \frac{2 b z}{2 \pi \sigma^{2}} \exp \frac{-(\operatorname{lnb}-m u)^{2}}{2 \sigma^{2}} d b$

This equation can be integrated by multiple levels of substitution. Integrating Equation 29 gives the area of the entire fracture of:

$A=z \exp \left(\sigma^{2} / 2+m u\right)$ 
For flow volume, the equation to be integrated is:

$Q=\int_{0}^{\infty} \frac{r b^{2} 2 b z d h}{3 \mu b \sqrt{2 \pi \sigma^{2}} d x} \exp \frac{-(\ln b-m u)^{2}}{2 \sigma^{2}} d b$

The same substitutions are used as before, and the integration of Equation 31 gives the total discharge through the fracture as:

$Q=\frac{r z d h}{3 \mu d x} \exp \left(3 m u+9 \sigma^{2} / 2\right)$

Dividing Equation 32 by Equation 30 gives the equation for mean velocity through the fracture:

$u=\frac{\gamma d h}{3 \mu d x} \exp \left(2 m u+4 \sigma^{2}\right)$

Back-substituting in Equation 25 for velocity within a single channel gives:

$v(b)=u b^{2} \exp -\left(2 m u+4 \sigma^{2}\right)$

This definition of $v(b)$ can then be used to calculate the distribution of tracer at the outlet of the fracture. The equation for the total discharge out of the fracture has already been solved (Equation 32 ), which when set in terms of average velocity gives:

$Q=u z \exp \left(\mathrm{mu}+\sigma^{2} / 2\right)$

The discharge from channels having an aperture greater than $b^{\star}$ is given by:

$Q^{*}=\int_{b^{*}}^{\infty} \frac{2 u b^{3} z \exp -\left[(\ln b-m u)^{2} / 2 \sigma^{2}\right]}{b \sqrt{2 \pi \sigma^{2}} \exp -\left(2 m u+4 \sigma^{2}\right)} d b$ 
where $b^{\star}$ is given by:

$b^{*}=\left(\frac{x}{u t} \exp \left(2 m u+4 \sigma^{2}\right)\right)^{1 / 2}$

Integrating Equation 36 from $b^{*}$ to infinity gives the discharge carrying tracer at time $t^{*}$. Dividing the result by the total discharge through the fracture, Equation 35, gives the equation for tracer concentration as a function of time at the outlet of the fracture:

$\frac{c}{C_{0}}=\frac{Q^{\star}}{Q_{t}}=\frac{1}{2} \operatorname{erfc}\left(\frac{1}{\sqrt{2 \sigma^{2}}}\left(\ln \frac{x \exp \left(2 m u+4 \sigma^{2}\right)}{u t}-m u\right)-\frac{3}{2} \sqrt{2 \sigma^{2}}\right)$

This equation is the volumetric average of the concentration, and therefore represents the flowing concentration discussed above. Figure 6 shows a family of tracer breakthrough curves that lllustrate the effect of the variance in fracture aperture on tracer breakthrough. 


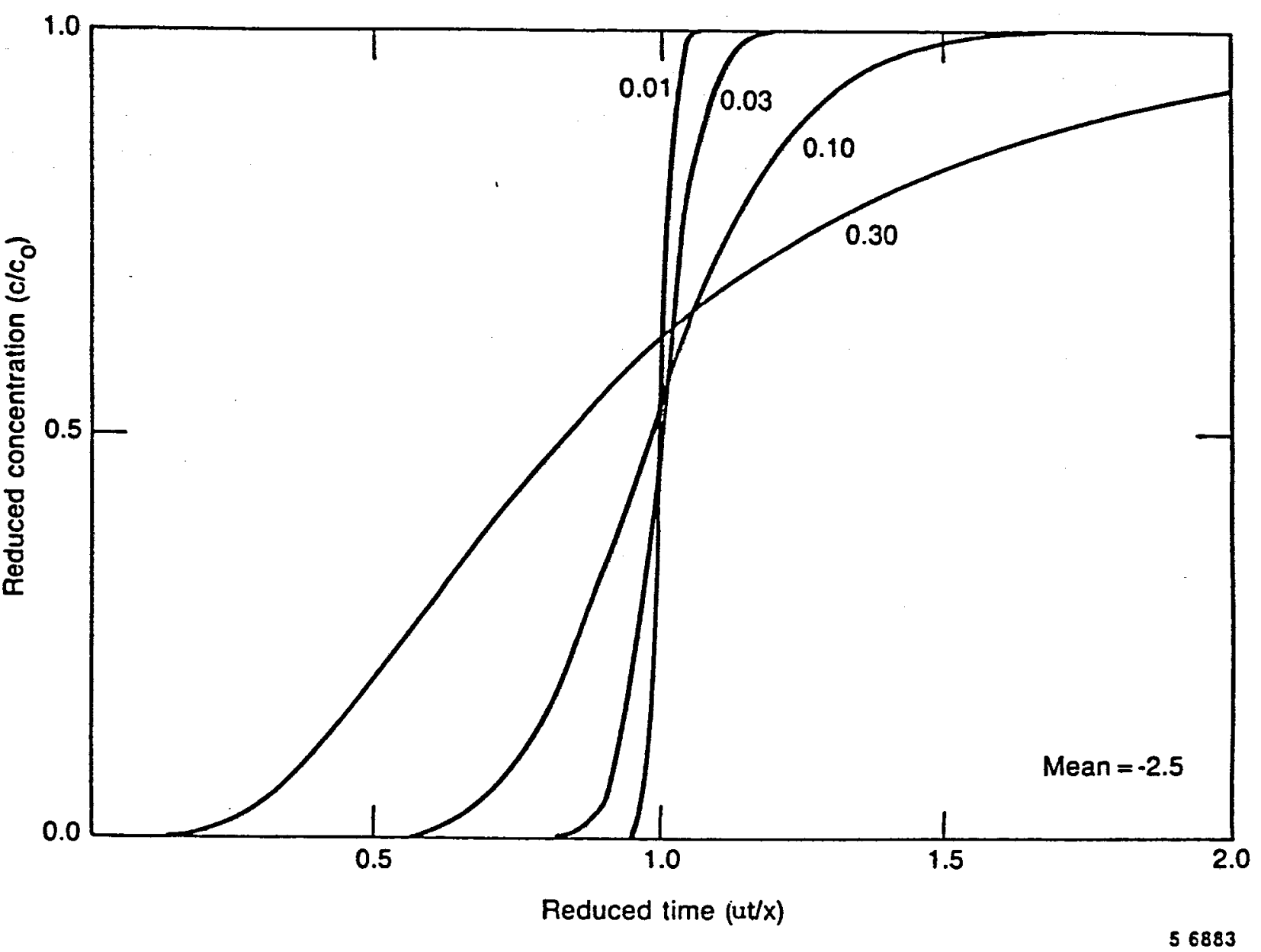

Figure 6. Effect of aperture variance on tracer breakthrough curves for fractures with lognormal distribution of aperture.

Calculated using Equation 38. 
Three computer codes are used for data analysis. These codes provide data analysis and simulation capabilities for a broad range of fracture geometries. Two codes are used for simulation of single fracture elements, and the third for simulation of dual permeability fracture systems, with or without matrix porosity. The single element codes will be discussed here, along with the theory behind the particle tracking algorithm. The reservoir simulation code is discussed in more detail by Clemo and Miller (1984) where details of the mechanics behind particle transfer between fractures and matrix are discussed.

\section{Particle Tracking Algorithm}

Finite element and finite difference schemes for numerical simulations can suffer from numerical oscillations and numerical dispersion, particularly at high mesh Peclet numbers (Noorishad and Mehran, 1982). The mesh Peclet number is defined similarly to the standard Peclet number in Equation 8 , but with the $x$ distance representing the grid spacing. As velocities tend to be greater in fractures than in porous media, the problems with oscillation tend to be greater than for porous media models. To avoid these problems, a particle tracking approach was adopted.

Particle motion from diffusion and dispersion in porous matrix blocks is assumed to follow a random walk (Bear, 1972; Ah1strom et a1., 1977). The probability of a particle being at a point $m$ after $N$ independent steps is given by:

$P(m, N)=\frac{N !}{[0.5(N+m)] ![0.5(n-m)] !} 0.5^{N}$

For very large $N$, such as would be the case for ion diffusion by Brownian motion. Equation 39 yields a Gaussian probability distribution:

$P(m, N)=\sqrt{\frac{2}{\pi N}} \exp \left(\frac{-m^{2}}{2 N}\right)$ 
If a particle undergoes $n$ displacements of length $\ell$ per unit $t$ ime, it will travel at a velocity of $v=n \ell$. The time required for $N$ displacements is $\mathrm{N} / \mathrm{n}$. A diffusion coefficient is defined as:

$D_{m}=n \ell^{2} / 2$

Using the relations discussed above and Equation 41 to replace $N$ in Equation $\mathbf{4 0}$ gives the classic one-dimensional solution to the diffusion equation:

$P(x, t)=\frac{1}{2 \sqrt{\pi D_{m} t}} \exp \left(\frac{-x^{2}}{4 D_{m} t}\right)$

This describe a Gaussian distribution of particles with a variance given by:

$\sigma^{2}=2 D_{m} t$

By multiplying sigma by a random normal variate with mean zero and variance one, the distance a particle travels during one time step can be simulated. The procedure is used to simulate both diffusion in fractures and dispersion in matrix blocks, with appropriate values for the diffuston/dispersion coefficient.

For two-dimensional simulations, diffusion in two directions is possible. In this case, Equation 43 is used to determine the distance the particle diffuses, and the direction is assumed to be uniformly distributed. The angle of diffusion is determined by multiplying $2 \pi$ by a uniformly distributed random variable between 0 and 1 .

For fracture simulations, starting and ending coordinates of the particle are calculated based on diffusion. The longitudinal velocity is then calculated for these starting and ending coordinates, determining the average particle velocity. The particle is then moved to its new position in the fracture. For particles that bounce off fracture walls or cross the centerline of the fracture, two averages are calculated. One for the path 
from the starting position to the wall or centerline, and one from the wall or centerline to the ending position. This takes into account the very low velocities along the wall and the peak velocities along the centerline.

\section{PNLFRAC}

The first code is derived from the Prickett, Naymik and Lonnquist 'Random Walk' model (Prickett et a1.,1981) modified to simulate flow and transport in fractures. Velocities at nodes are calculated from analytical solutions to the velocity equation between parallel plates (2-D) or for flow in rectangular channels (3-D). Both two-dimensional and three-dimensional veloctty flelds can be employed, giving capabilities for both infinite parallel plates and rectangular channels, such as in the physical models. The code can handle single fractures only. Solute transport is by particle tracking. Advection is calculated from the velocity at the particle position in the fracture times the time step. The lateral position of the particle is changed by transverse diffusion within the fracture. This approach allows easy simulations in both two and three dimensions, and is valid over the entire range of laminar flow veloctties. Because of symmetry, only one-half or one-quarter of the fracture need be simulated. There is no explicit treatment of dispersion; dispersion is handled on a mechanistic level by velocity profile and diffusion.

For two-dimensional flow simulations, velocity at a point in the fracture is calculated from Equation 2. For rectangular channels, the three dimensional velocity profile is calculated from an equation presented by Happel and Brenner (1965).

$$
\begin{aligned}
v(y, z)= & \frac{r d h}{2 \mu d x} y(y-2 b) \\
& +\sum_{m=1}^{\infty} \frac{r(2 b)^{2} d h}{m(\pi m)^{3} d x}[\cos (m \pi)-1] \sin (m \pi y / 2 b) \\
& \cdot[1+\exp (-m \pi n)]^{-1}[\exp (-m \pi z / 2 b)+\exp (-m \pi(n-z / 2 b))]
\end{aligned}
$$


where:

$$
n=2 a / 2 b
$$

Figure 7 shows a comparison between the velocity profile between parallel plates and for a rectangular channel having the same aperture, but with an aspect ratio of $6: 1$. The peak velocity in the rectangular channel is greater than between parallel plates to compensate for extremely low velocities in the corners. The vertical velocity profile is almost square, but shows lower velocities due to boundary effects on the top and bottom surfaces. Figure 8 illustrates the effects of friction losses along upper and lower boundaries for rectangular channels of varying aspect ratios. At a constant gradient, the mean flow velocity will decrease as the aspect ratto decreases. Rectangular channels of aspect rat10 of $50: 1$ and above are within about $1 \%$ of flow velocities for infinite parallel plates. Table 1 shows point velocities for one-quarter sections of rectangular channels with aspect ratios of $6: 1,12: 1,50: 1$, and velocities for infinite parallel plates for comparison.

A constant concentration boundary condition is used at the inlet of the fracture. This is achieved by releasing particles into each cell based on the discharge through that cell. Cells near the fracture walls get only a few particles while those in the center of the fracture get up to 1.5 times the average number of particles, for parallel plates. The particles are released randomly over the width (and height) of the cell, and randomly over the time step.

Output from the model consists of breakthrough curves at electrodes both embedded in the fracture and at the fracture outlet. Maps of particle locations within the fracture can be produced at various times.

To simulate data from laboratory models that have three-dimensional characteristics using the FRACSL code, which is a two-dimensional code, some modification of the velocity profile equation is necessary. Empirical two-dimensional velocity profile equations were developed to describe the 



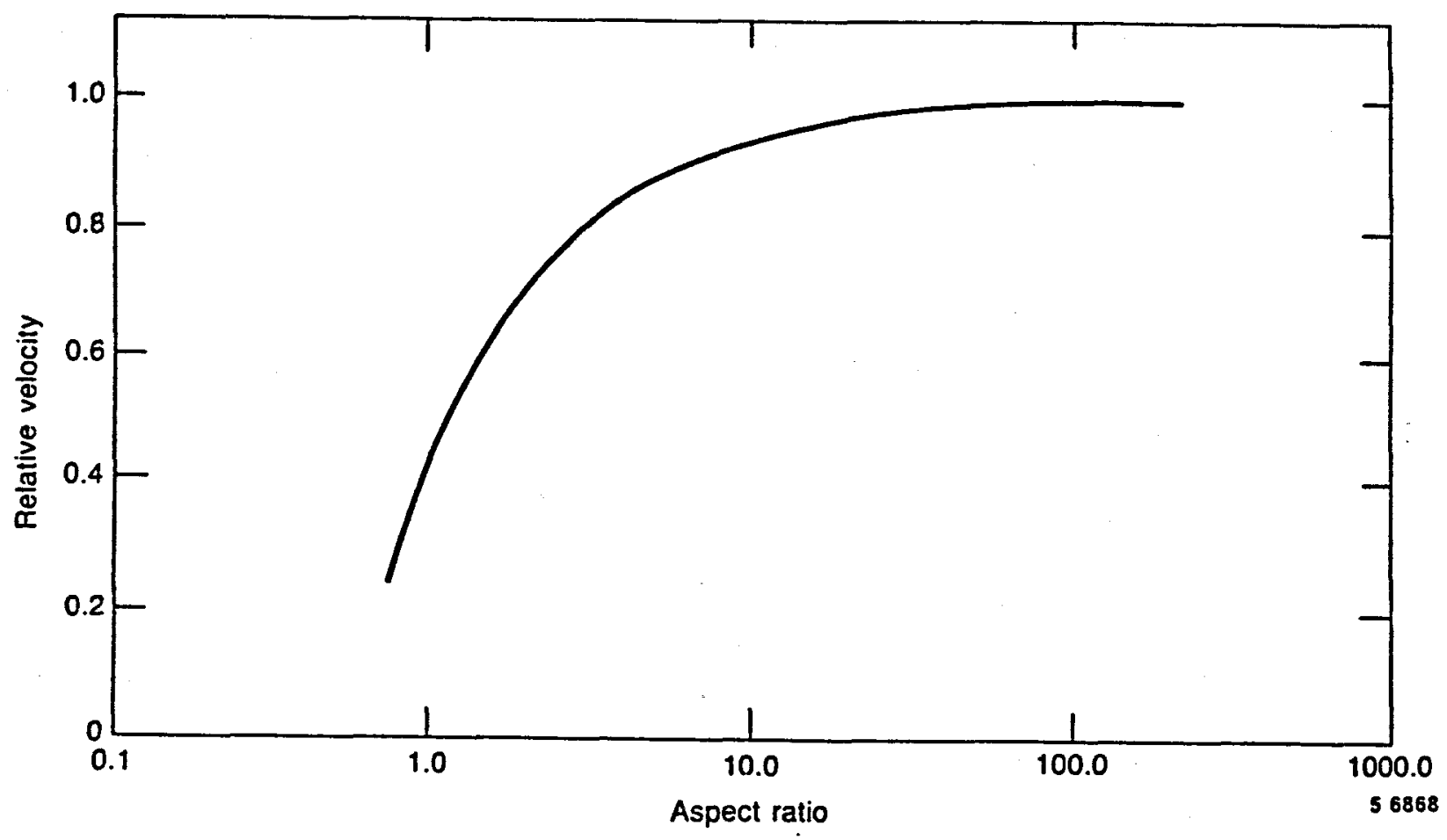

Figure 8. Ratio of average fluid velocities in rectangular channels of various aspect ratios to average fluid velocity for infinite parallel plates.

three-dimensional velocity profile projected into two dimensions. These equations were developed by running three-dimensional simulations, and fitting the results with third-order polynomial equations.

To determine the shape of the three-dimensional velocity profile when projected onto two dimensions, the particle tracking capabilities of PNLFRAC were used. A pulse of tracer particles was released uniformly across the inlet to a rectangular channel. The diffusion coefficient was set to zero, so particles did not move laterally in the fracture. This produced a set of particles that uniformly sampled all veiccities in the velocity profile. By counting the number of particles that arrived at the end of the fracture over a given time interval, the fraction of flow having velocities within a certain velocity range was determined. By integrating. inverting, and normalizing the particle data, the two-dimensional velocity 
TABLE 1. NORMALIZED FLUID VELOCITIES IN RECTANGULAR CHANNELS HITH VARIOUS ASPECT RATIOS

\begin{tabular}{lllll}
\hline$/ b$ & $6: 1$ & $12: 1$ & $50: 1$ & $\underline{0: 1}$ \\
1.0 & 0.0 & 0.0 & 0.0 & 0.0 \\
0.9 & 0.318 & 0.301 & 0.288 & 0.285 \\
0.8 & 0.603 & 0.570 & 0.545 & 0.540 \\
0.7 & 0.855 & 0.807 & 0.772 & 0.765 \\
0.6 & 1.073 & 1.013 & 0.968 & 0.960 \\
0.5 & 1.257 & 1.187 & 1.135 & 1.125 \\
0.4 & 1.408 & 1.330 & 1.271 & 1.260 \\
0.3 & 1.525 & 1.440 & 1.377 & 1.365 \\
0.2 & 1.609 & 1.520 & 1.453 & 1.440 \\
0.1 & 1.659 & 1.567 & 1.498 & 1.485 \\
0.0 & 1.676 & 1.583 & 1.513 & 1.500 \\
\hline
\end{tabular}


profile was calculated. Examples of two-dimensional velocity profiles for rectangular conduits for aspect ratios of $6: 1,12: 1$, and $50: 1$ are shown in Figures 9 to 11 . Table 2 gives the coefficients for the polynomials. Figure 9 also shows the shape of the true parabolic velocity proflle in comparison to that for an aspect ratio of $6: 1$. For rectangular channels, the peak velocities along the center of the fracture are greater, which compensates for slower velocities in the midrange. Because the transverse distances the tracer must travel in the pseudo three-dimensional fracture are smaller than in an actual three-dimensional fracture, the diffusion coefficient must also be modified. This has been done by a brute force fitting method, but has not been evaluated from a geometrical standpoint.

\section{SALE}

The second code is a fluid dynamics code from Los Alamos National Laboratory, written by Amsden et al., (1980). The acronym for this code s.tands for Simplified Arbitrary Lagrangian Eularian. Both two-dimensional and three-dimensional versions are available, although all simulations carried out to date have been with the two-dimensional version. The code had no provisions for solute transport, and so the same particle tracking algorithm used in the PNLFRAC code was adapted to the SALE code. The SALE code was initially used for single fractures until it was confirmed that an analytical solution to the flow equation would produce the same results. Most of the use of SALE has been to simulate single fracture junctions.

\section{FRACSL}

The third code is a reservoir level simulation code for dealing with flow in porous media, discrete fractures, and dual porosity media (Miller. 1983; Clemo and Miller, 1984). It uses the (ACSL) simulation language (Mitchell and Gaither Assoc., 1981) to solve the numerical equations, and so is called FRACSL. It is a two-dimensional finite difference code. It is currently undergoing verification tests. Current capabilities include transient and steady solutions for flow in porous, fractured, and dual-permeability media, transport of conservative solutes, and advective 


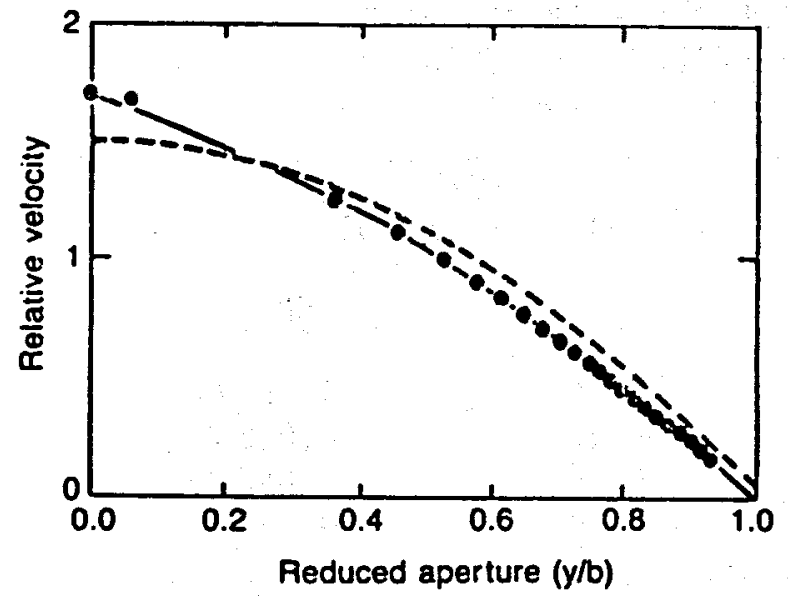

56872

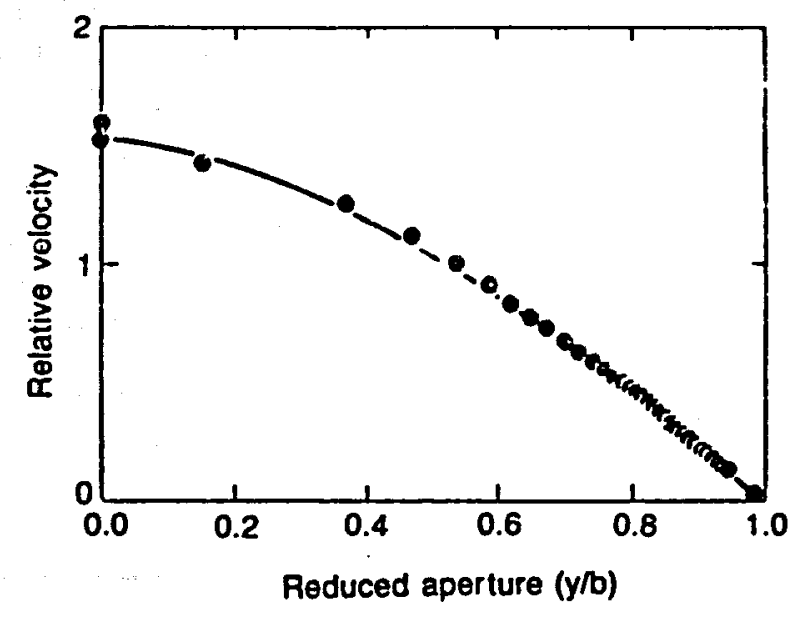

56873
Figure 9. Normalized pseudo-three dimensional velocity proflle for simulating rectangular channels with a $6: 1$ aspect ratio using a twodimensional code.
Figure 10. Normalized pseudo-three dimensional velocity profile for simulating rectangular channels with a $12: 1$ aspect ratio using a twodimensional code.

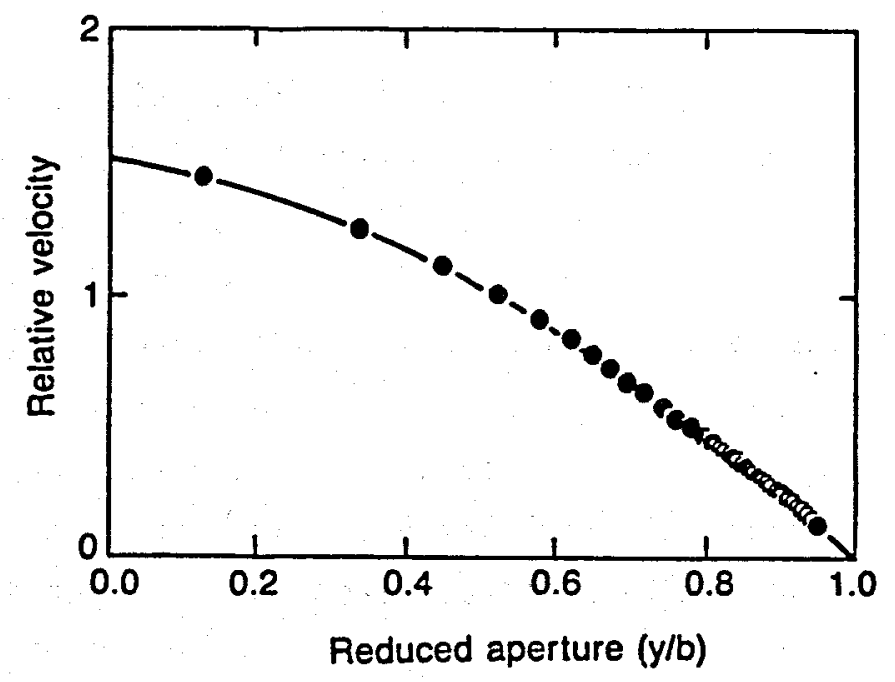

56871

Ftgure 11. Normalized pseudo-three-dimensional velocity profile for simulating rectangular channels with a $50: 1$ aspect ratio using a two-dimensional code. 
TABLE 2. COEFFICIENTS OF POLYNOMIAL EQUATIONS TO DESCRIBE THE 2-D

PROJECTION OF 3-D VELOCITY PROFILES FOR RECTANGULAR CHANNELS

The equations have the form:

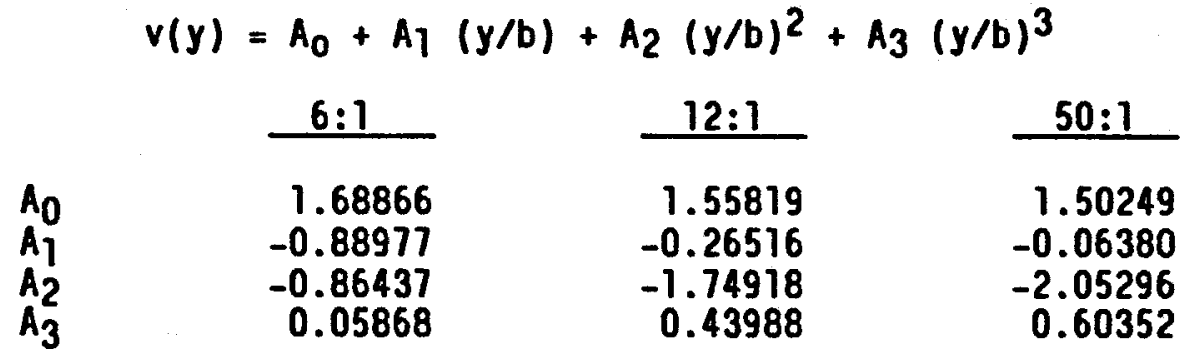

transport of solutes between fractures and matrix blocks. Fractures can be verticle, horizontal, or diagonal across a cell. The code solves for one pressure distribution for both matrix and fractures. Solute transport is by particle tracking, as for the two previously described codes.

\section{PHYSICAL MODEL CONSTRUCTION}

Many of the physical models constructed contain common characteristics. The common characteristics of the physical models are discussed here, with details on individual models given in the sections devoted to the individual model studies. All models have been built of plexiglass, which allows visual observation of tracer movement by using a dye added to solutions. Plexiglass is easy to work with, impermeable, and nonconductive of electricity. Sheets of plexiglass ranging from $1 \mathrm{~cm}$ to $2.54 \mathrm{~cm}$ have been used. Plexiglass sheets are first secured to solid bases of either plywood or aluminum to add strength and to prevent the plexiglass from bending. The fractures are then cut into the plexiglass using a milling machine. Tolerances on fracture depth and width are within $\pm 0.1 \mathrm{~mm}$. Fractures are not cut through the plexiglass, which precludes the need for sealing the bottoms of the fractures. The tops of the fractures are sealed with thin plexiglass cut to match the shape of the fracture or fracture network, producing a lattice effect. With the lattice structure, glue (ethelyne dichloride) is pulled under the cover plate by capillary action, giving a good seal and preventing short circuiting across the tops of the matrix blocks. 
In early physical models, injection was through polyethelene nipples epoxied to the plexiglass. The nipples were fed through a short length of Tygon tubing extending from a 3-way stopcock. The 3-way stopcock permitted a flow field to be developed using the native fluid, and then a rapid switch to the tracer solution. As measurement capabilities improved, however. it became apparent that the circular geometries of the stopcock and inlet tubing where significantly affecting the tracer breakthrough curves. Special stopcocks were designed to alleviate this problem. The stopcocks are made of plexiglass, and are attached directly to the plexiglass mode1, with no intervening tubing. The channels of the stopcock are al1 rectangular, with the same geometry as the model being used. Thus there are no changes in flow configuration as the fluid is injected into the mode1s. This configuration is necessary to get a sharp step change in input concentration.

Two solutions are used in the models to study the mixing characteristics between two miscible fluids. The native fluid consists of distilled water dyed yellow with food coloring. Tracer solution is a dilute solution of $\mathrm{KCl}$ in distilled water with blue food coloring added. Thus, movement and mixing of the two solutions can be monitored both visually by observing the color changes, and by measuring the resistivity of the fluid. The distillation process deaerates the water, and air bubble formation during testing has not been a problem. Entrapment of air during the initial filling operation can be a problem, however. Physical models are purged with carbon dioxide gas prior to filling, which flushes all air out of the mode1. Any carbon dioxide gas bubbles trapped in the model during subsequent filling operations are rapidiy dissolved.

Plezometers are installed in fractures to measure pressure distributions. Holes are drilled through the cover plate of the model directly over fractures, and copper tubing, $2 \mathrm{~cm}$ long and $1.5 \mathrm{~mm}$ in diameter is cemented flush with the upper wall of the fracture. Polyethelene tubing connects the copper plezometers to glass tubes fastened to a solid base covered with graph paper. The graph paper is $10 \times 10$ to the centimeter, so that differences in pressure can be read directiy in $\mathrm{cm}$ of water. 
Platinum electrodes, $3.2 \mathrm{~mm}$ in diameter, are embedded in upper and lower fracture walls (figure 12) to measure fluid resistivity. This permits very precise measurement of tracer concentration changes within the fractures without disturbing the flow fleld. Early models used flow-through conductance cells, which had a finite mixing volume with in the electrode, and could only be placed at outlets from the model. The current electrodes have no mixing volume other than the fracture itself, and can be located anywhere within the models.

Support equipment for the physical models is shown in Figure 13. Flow is controlled efther by pressure drop between constant head reservoirs or by syringe pumps. Flow measurement is by 'ball in tube' flow meter and graduated cylinder. Two methods of flow measurement are used for better control of flow. Flow rates can be set to an accuracy of only $\pm 10 \%$, a)though reproducibility of measurements is on the order of 2-5\%. Native solution and tracer solution reservoirs are set to equal heads at the inlet side of the model so that a steady flow field can be established in the model using the native fluid. The switch from native to tracer solutions can be made in less than one second, which minimizes and inertial effects of intiating flow in fluid at rest.

Changes in conductance are measured by scanning electrodes with a computer controlled scanner. Multiplexing of electrodes is necessary to avold cross-talk between the electrodes, which are all embedded in the same conducting fluid. A Hewlet Packard HP-1000 has been used as the controller for the data acquisition system. Access to the HP-1000 has been lost, and currently an IBM-PC is being programmed to take over the roll of system controller. Communication with the scanner and digital volt meter (DVM) is across an IEEE-488 interface bus. The scan interval can be as short as once every six seconds, for a configuration with 20 electrodes. Data recorded include the time when the test began, and the time and fluid conductivity each time an electrode is accessed. 


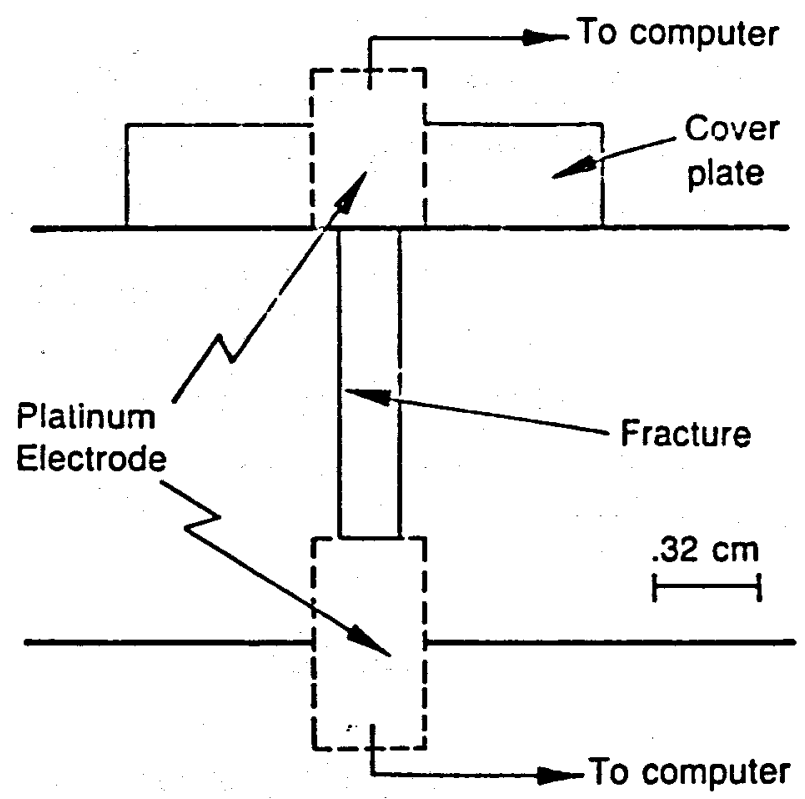

56878

Figure 12. Diagram showing installation of a specific conductance electrode.

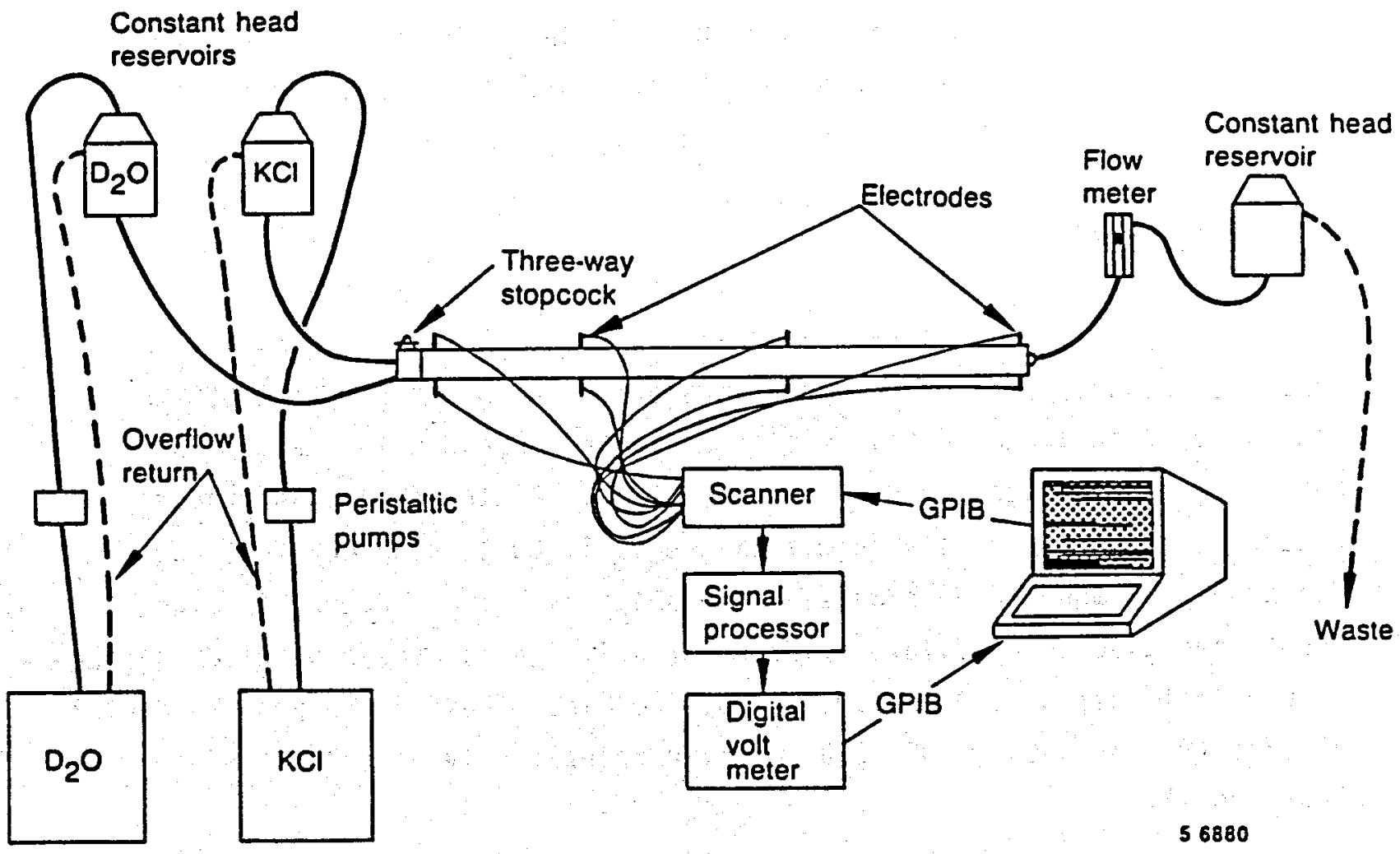

Figure 13. Experimental support equipment for physical model studies. 


\section{SINGLE FRACTURE ELEMENTS}

Detalled study of single fractures and single fracture junctions provides some important insight into the processes that control dispersion. Studies were conducted on single fractures to validate the parallel plate equations under conditions of smooth, parallel fracture wal1s. Studies were conducted on a single or thogonal fracture junction to evaluate the conditions under which complete mixing at fracture junctions would be a reasonable assumption. Both laboratory models and computer codes were used in the studies.

\section{Single Fractures}

To study dispersion in single fractures, experiments were conducted on a laboratory model constructed of plexiglass. Concentrations of tracers were measured in the single laboratory fracture as a function of time at four flow rates. Computer simulations were then run to determine if the computer code could accurately predict tracer movement. The code was then used to study the limiting Peclet number concept, as discussed previousiy, for application of a one-dimensional advection-dispersion equation to fractures.

\section{Laboratory Model}

The laboratory model consisted of a single fracture (Figure 14) cut into plexiglass. The fracture has an aperture of $0.159 \mathrm{~cm}$, is $0.953 \mathrm{~cm}$ high, and $68 \mathrm{~cm}$ long. Platinum electrodes are embedded in the top and bottom of the fracture $58 \mathrm{~cm}$ from the origin. A step change in tracer concentration is accomplished with a specially built stopcock that has rectangular channels the same size and shape as the laboratory fracture. The tracer used was a dilute solution of $\mathrm{KCl}$. Tests were conducted at four flow velocities; $0.1,0.3,1.0$, and $3.0 \mathrm{~cm} / \mathrm{min}$. These correspond to Peclet numbers $\left(P_{f}\right)$ of $5800,1900,580$, and 190 respectively as calculated from Equation 18. 


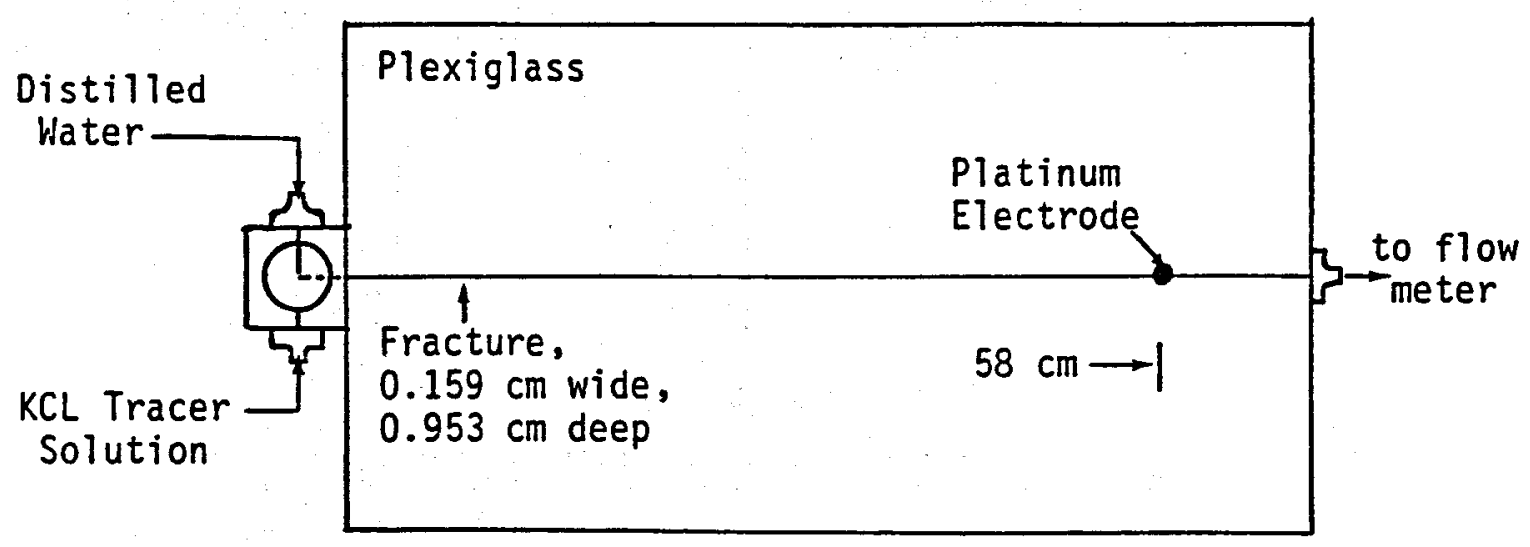

Figure 14. Single fracture model for studying dispersion.

Figures 15 through 18 show comparisons between the computer simulations of a three-dimensional fracture and measurements made on the laboratory fracture. Agreement between the lab and computer results is very good.

\section{PNLFRAC Simulations}

To demonstrate the limitations of applying a one-dimensional solution of the advection-dispersion equation to fractures, some two-dimensional fracture simulations were carried out using the particle tracking model.

A sertes of runs was made at fracture Peclet numbers (Equation 18) of $0,5,50$, and 500. A Peclet number of zero was achieved by setting the diffusion coefficient to zero. Figure 19 shows a map of tracer concentration in a fracture for $P e=0$. This is a purely advective system, with dispersion resulting from the velocity profile. The front is quite steep, but the position ranges from 1.5 ut to 0 along the fracture wall. The breakthrough curve is shown in figure 20 along with the analytical solution for advecilve transport in a fracture (Equation 5). The computer prediction shows vcry good agreement to the analytical solution with only a slight anticipdtion of the actual time of breakthrough. The scatter in the 


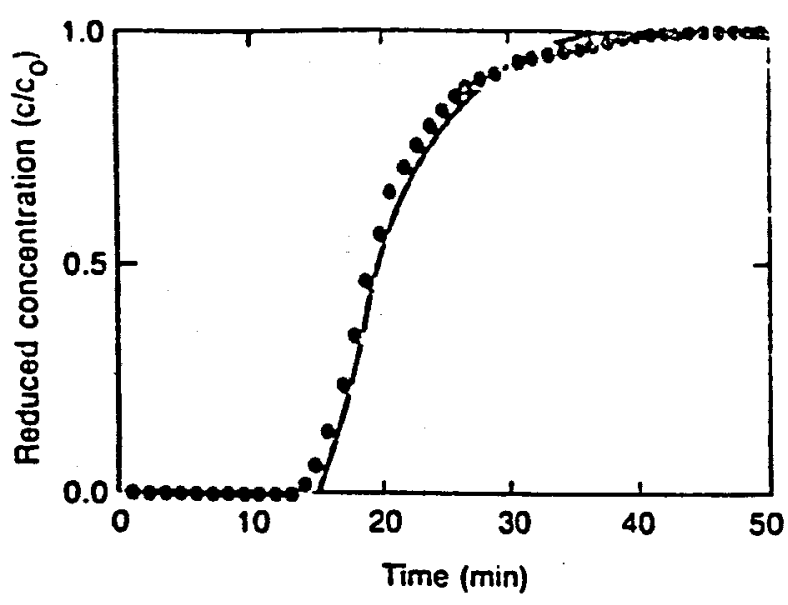

Figure 15. Comparison of tracer breakthrough measured in the singlefracture laboratory model (1 ine) with PNLFRAC simulated breakthrough (points) at an average flow velocity of $3.0 \mathrm{~cm} / \mathrm{min}$.

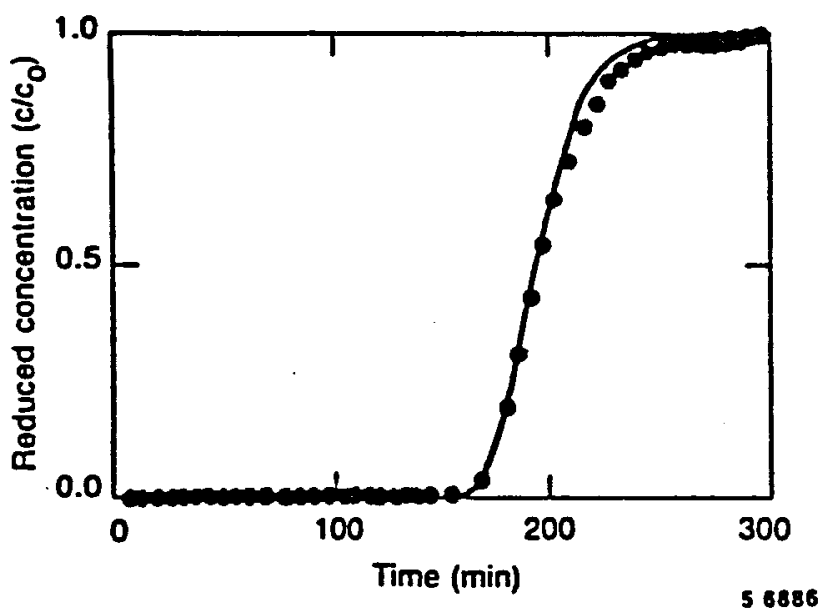

Figure 17. Comparison of tracer breakthrough measured in the single-fracture laboratory model (line) with PNLFRAC simulated breakthrough (points) at an average flow velocity of $0.3 \mathrm{~cm} / \mathrm{min}$.

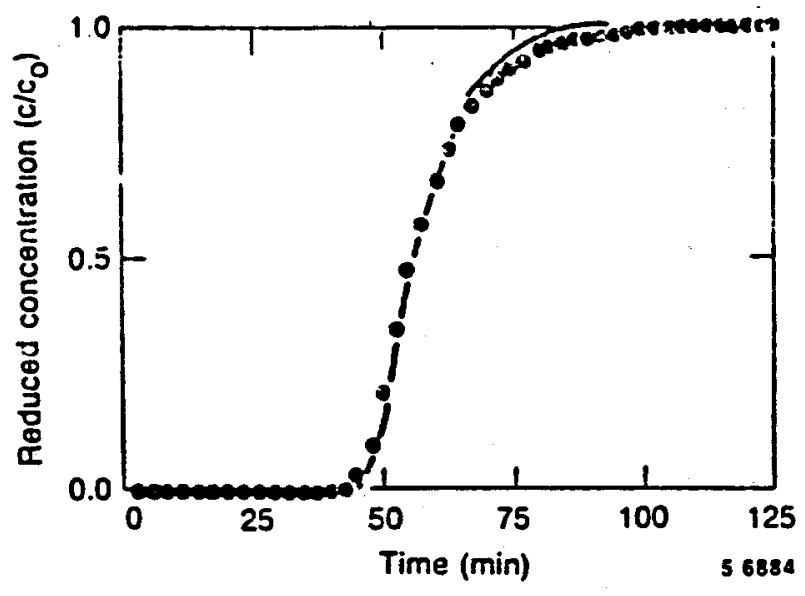

Figure 16. Comparison of tracer breakthrough measured in the singlefracture laboratory model (iine) with PNLFRAC simulated breakthrough (points) at an average flow velocity of $1.0 \mathrm{~cm} / \mathrm{min}$.

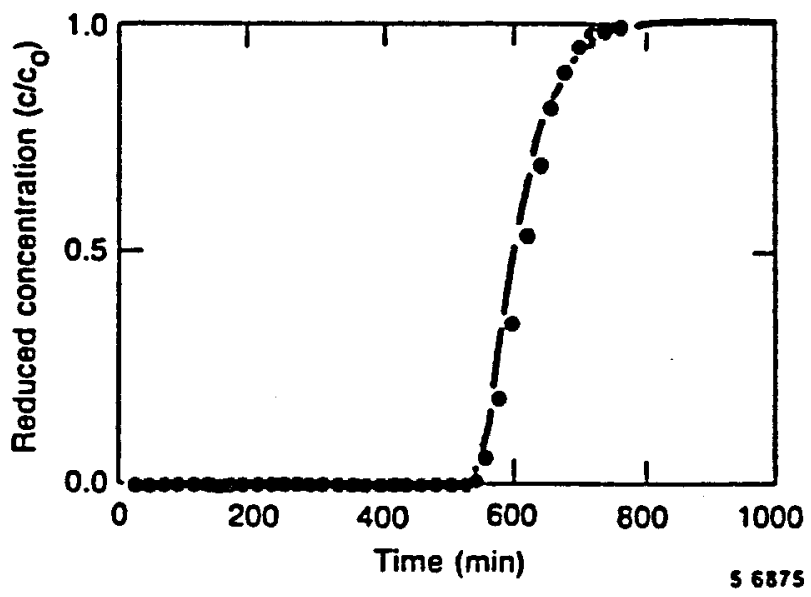

Figure 18. Comparison of tracer breakthrough measured in the single fracture laboratory model (inine) with PNLFRAC simulated breakthrough (points) at an average flow velocity of $0.1 \mathrm{~cm} / \mathrm{min}$. 

computer predicted values is due to statistical fluctuations introduced by the random components of injection location and diffusion.

At the other end of the range of Peclet numbers, the computer simulations can also be compared to an analytical solution. Figure 21 shows a map of tracer concentration in the fracture at $\mathrm{Pe}=500$. Transverse diffusion has homogenized the tracer concentration, and the tracer front is at the same axial distance along the fracture at all locations. Figure 22 shows a comparison between the computer simulation and an analytical solution using Equation 17 to calculate the longitudinal dispersion coefficient used in Equation 7. Again, very good agreement is obtained between the computer simulations and the analytical solutions. The code has matched analytical solutions where advection dominates over diffusion, and where diffusion homogenizes the tracer across the fracture.

At Peclet numbers greater than 500, Equation 7 will be valid for parallel plates, and Equation 17 can be used to calculate the dispersion coefficient. For Peclet numbers below 157.5. Equation 7 is invalid. An example of the difference between the one- and two-dimensional results for a case where two-dimensional effects are significant can be seen for a simulation at a $\mathrm{Pe}$ of 5 . The map of the tracer concentration in the fracture is shown in Figure 23. Along the fracture wall near the inlet to the fracture, the tracer concentration has started to rise. This distorts the parabolic shape of the tracer front as can be seen by comparing Figures 19 and 23. The effects of transverse diffusion can be seen in Figure 24. The analytical solution (Equation 5) no longer fits the data as transverse diffusion has distorted the shape of the front. A one-dimensional solution to the advection-dispersion equation does not fit the data either as shown in Figure 25. The analytical solution shows a much earlier rise in tracer than actually occurs. In fact, the analytical solution shows a much earlier rise in tracer than can occur. Hydrodynamics of parallel plates constrain the maximum velocity in a fracture to 1.5 times the mean velocity. In terms of reduced time, the earliest that tracer can arrive is at $\mathbf{0 . 6 7}$. There is no such constraint on the peak velocity for the classic advection-dispersion equation. This then is the significance of the limiting Peclet number. Onily under conditions where 


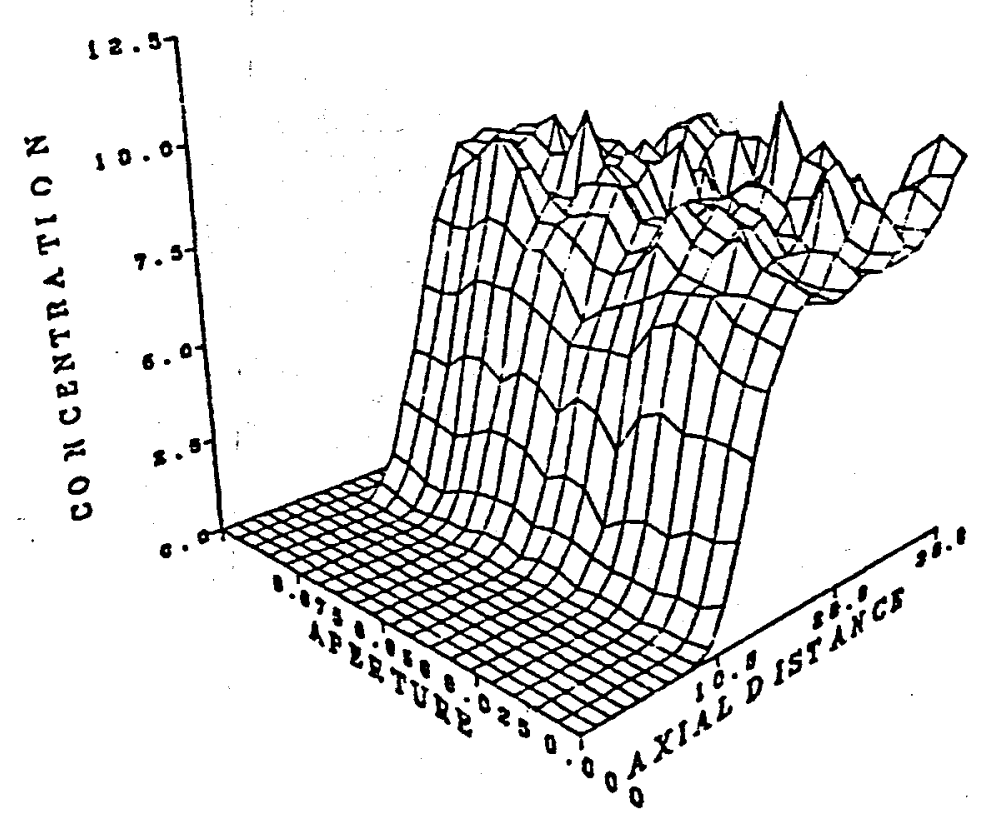

Figure 21. Map of tracer concentration in a fracture where transverse molecular diffusion dominates development of a parabolic velocity profile $(\mathrm{Pe}=500)$.

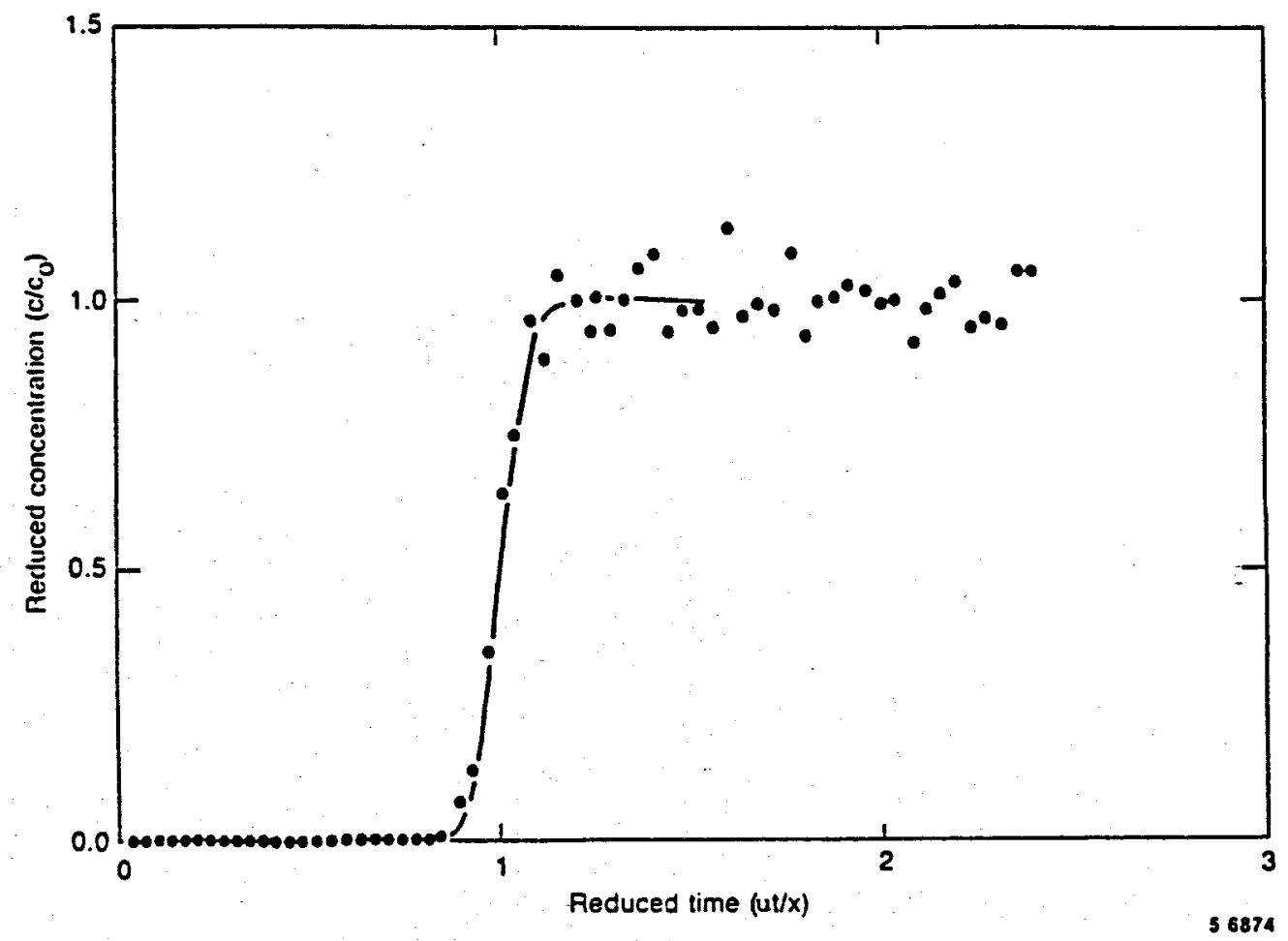

Figure 22. Comparison of analytical (1ine) and numerical (points) solutions for tracer breakthrough where transverse molecular diffusion dominates development of a parabolic velocity profile $(\mathrm{Pe}=500)$. 


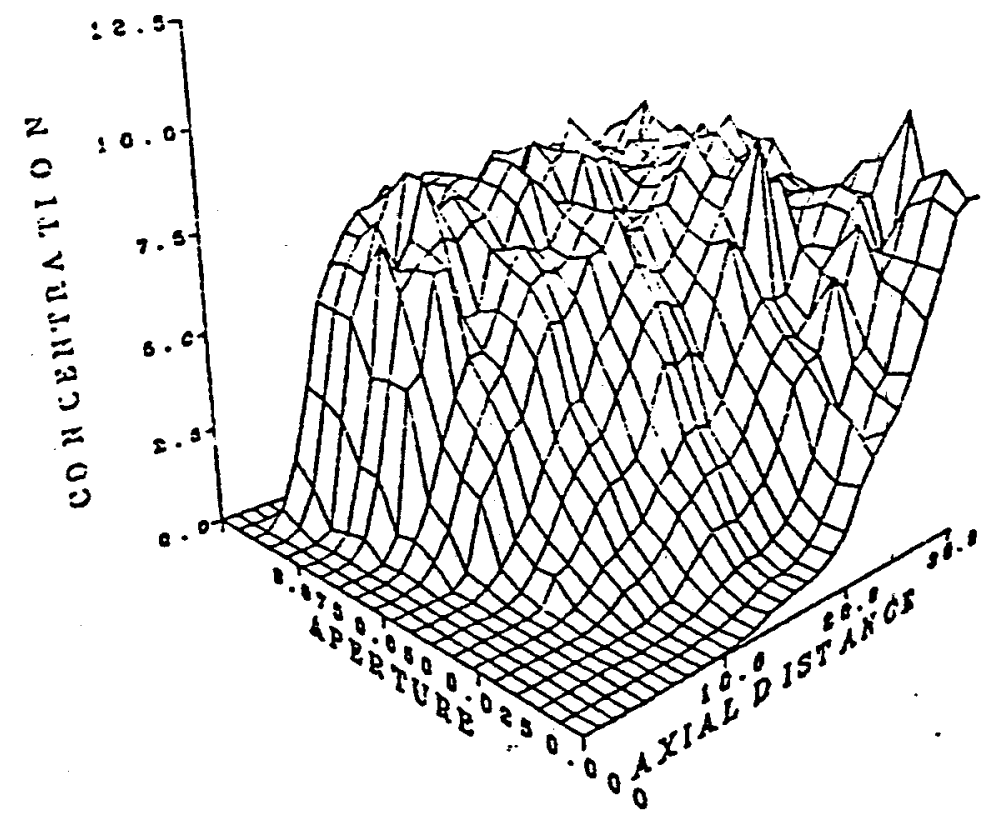

Figure 23. Map of tracer concentration in a fracture where both transverse molecular diffusion and the parabolic velocity profile affect tracer dispersion $(\mathrm{Pe}=5)$.

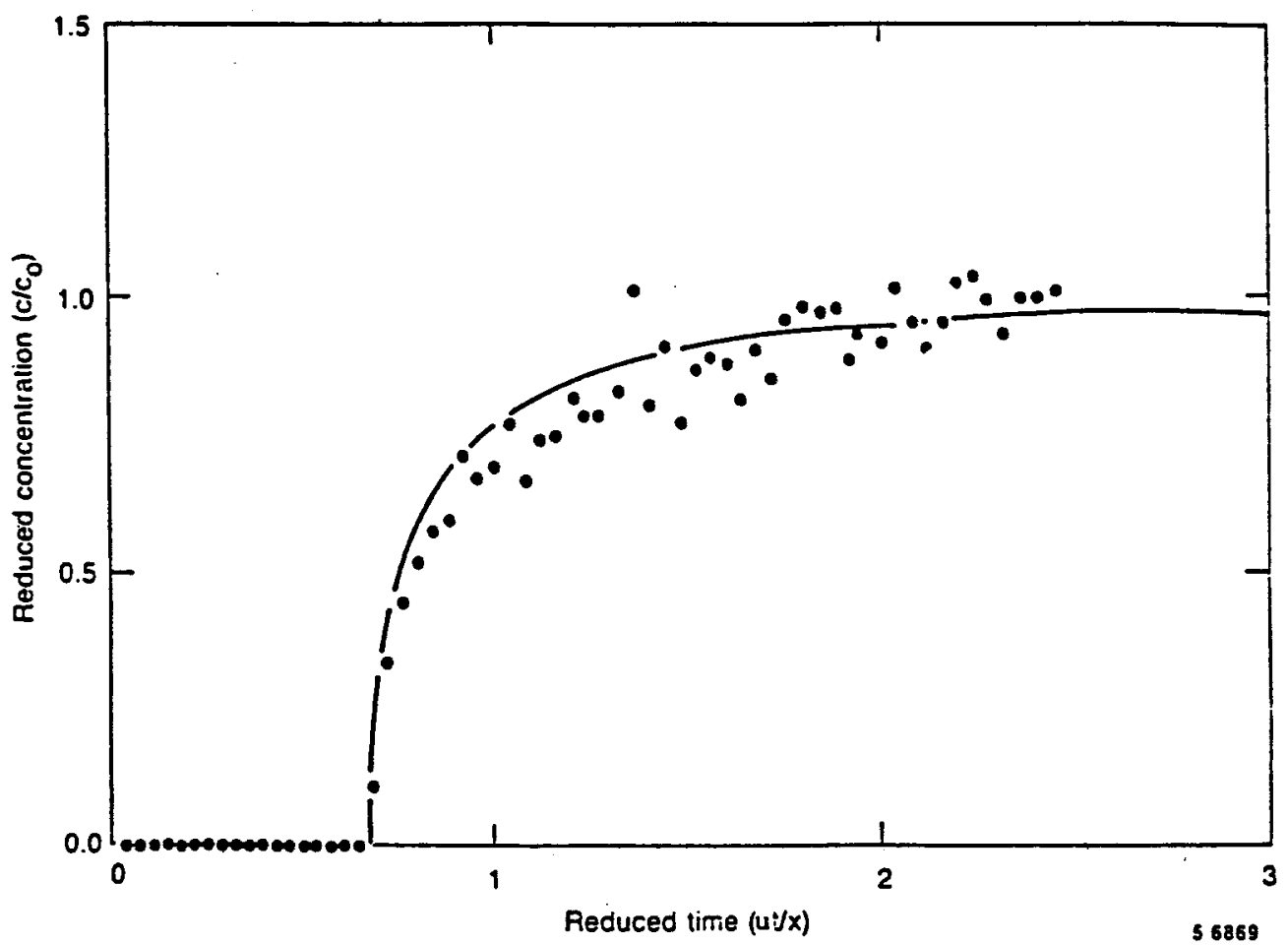

Figure 24. Comparison of the analytical solution for transport at $\mathrm{Pe}=0$ (line) with a numerical simulation of velocity profile and diffusion effects at $\mathrm{Pe}=5$ (points). 

transverse diffusion homogenizes the tracer front in a fracture (Figure 21), can the one-dimensional assumption be made.

\section{Fracture Junction}

Krisak et a1., (1972) conducted a series of experiments in laboratory fracture junctions to determine if mixing was occurring at the junctions. Their experiment was to have inflow from one fracture divided into two or three outflow fractures, all at equal heads. They concluded that because there was no significant difference in concentration profiles between outflow fractures, complete mixing had occurred in the junction. Under laminar flow conditions, streamilines in a fracture junction cannot cross (Endo, 1984). Therefore, diffusion is the only mechanism to transfer tracer solution between streamilines. Observation of tracer movement through fractures by Wilson and Witherspoon (1976) and by Hull and Koslow (1982) indicated no mixing of tracer between converging streams. The experiments conducted by Krizak et a1. (1972) were at flow rates even higher than those of Hull and Koslow (1982), so diffusion was not a 1ikely explanation. A laboratory model and computer simulation study was conducted to evaluate mixing at fracture junctions.

\section{Laboratory Model}

Laboratory experiments were conducted on a single or thogonal fracture junction to evaluate mixing at the junction. The laboratory model was constructed similarly to the single fracture model. Two orthogonal fractures were cut into a sheet of plexiglass. Fracture aperture was $0.159 \mathrm{~cm}$ and height $0.953 \mathrm{~cm}$, giving an aspect ratio of $6: 1$. Inflow from one or two inlet fractures could be controlled separately. Outflow from two or more outlet fractures was not controlled, but the heads were kept equal. The fracture junction was simulated using the two-dimensional version of SALE (Amsden et a1., 1980). Because only a two-dimensional code was used, experiments were all run to steady state conditions, rather than studying transients. Three-dimensional effects in the laboratory fracture were therefore avoided. Measurements of fluid resistivity indicated the 
division of inflow between outflow channeis, and visual observations gave information on the relative lateral position of tracer. Figure 26 shows a photograph of tracer distribution during a test. Flow from the left was 1.5 times the flow volume from the bottom. The flow velocitles were $34.5 \mathrm{~cm} / \mathrm{min}$ and $22.6 \mathrm{~cm} / \mathrm{min}$ respectively. These flow rates give a residence $t$ ime in the fracture junction of 0.5 seconds. Which translates to a dimensioniess time of 0.011 . No diffusion mixing would be expected for these short residence times.

\section{Computer Simulation}

Computer simulations were conducted using the SALE computer code (Amsden et a1.. 1980) at a range of flow rates to evaluate the effect of diffusion. Figure 27 shows the computer prediction of tracer movement through a fracture junction under the same conditions as shown in Figure 26. Very good agreement is obtained between the predicted and observed distribution of tracer in the outlet fractures.

Because diffusion is a very slow process. It will only have significant effects at very slow fluid flow rates. Figure 28 shows computer results of a simulation of a fracture junction where the flow from the two converging fractures was $1 \mathrm{~m} /$ day. Equal flow rates is the most sensitive condition for diversion of tracer from one fracture to another by diffusion. Diffusion between adjacent streamilines across the diagonal of the fracture junction diverts tracer from the righthand fracture to the upper fracture. Very 1ittie tracer is actually diverted, and what is diverted remains along the fracture wall where fluid flow rates are very low.

\section{Limiting Conditions for Mixing}

Based on diffusion coefficlents, fracture apertures, and flow rates, the conditions under which complete mixing at fracture junctions is justified can be calculated. These calculations are based on the condition that transverse diffusion between streamilnes homogenizes the tracer within 


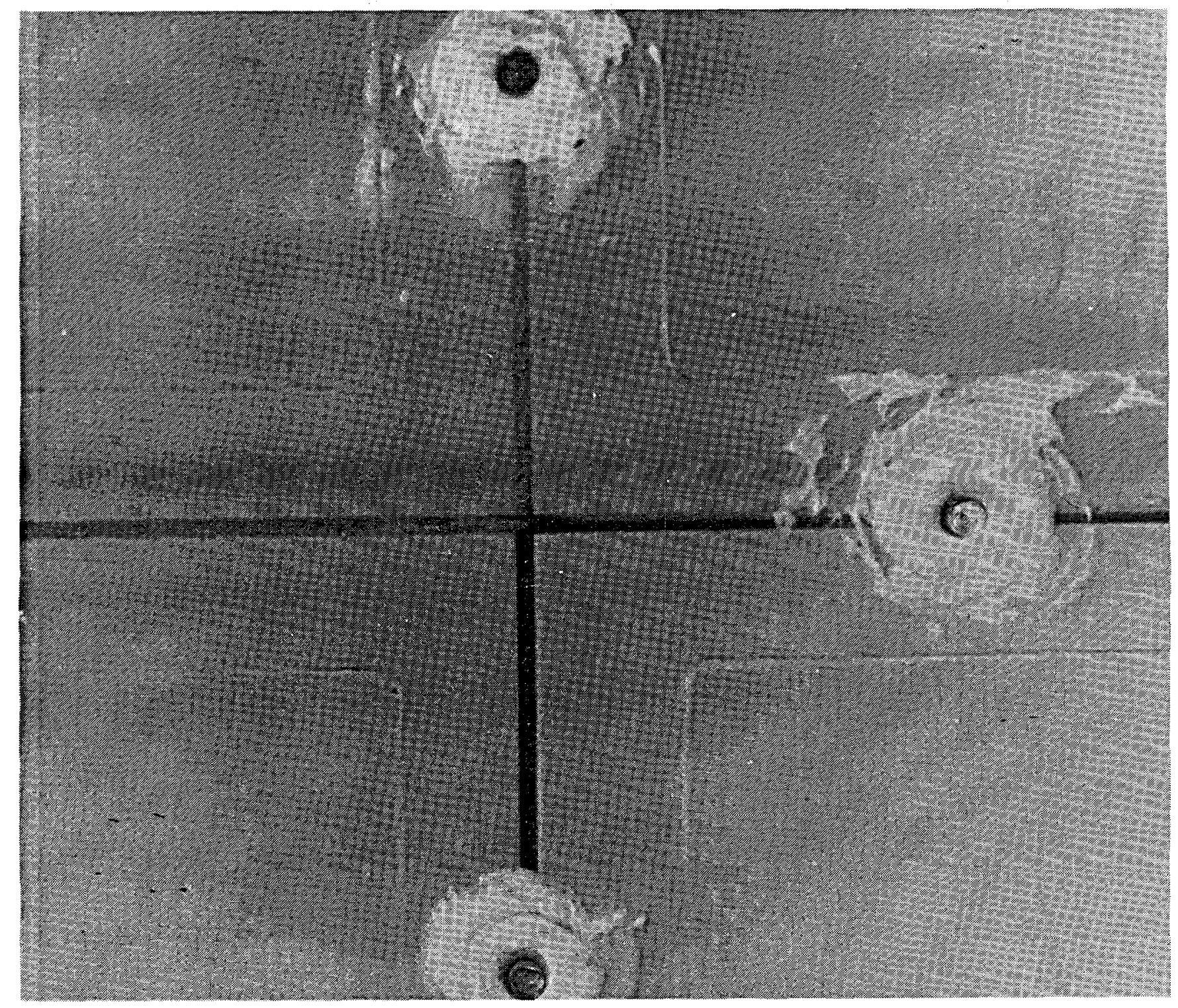

Figure 26. Photograph of the laboratory fracture junction showing distribution of tracer when inflow from the left is 1.5 times inflow from the bottom. 



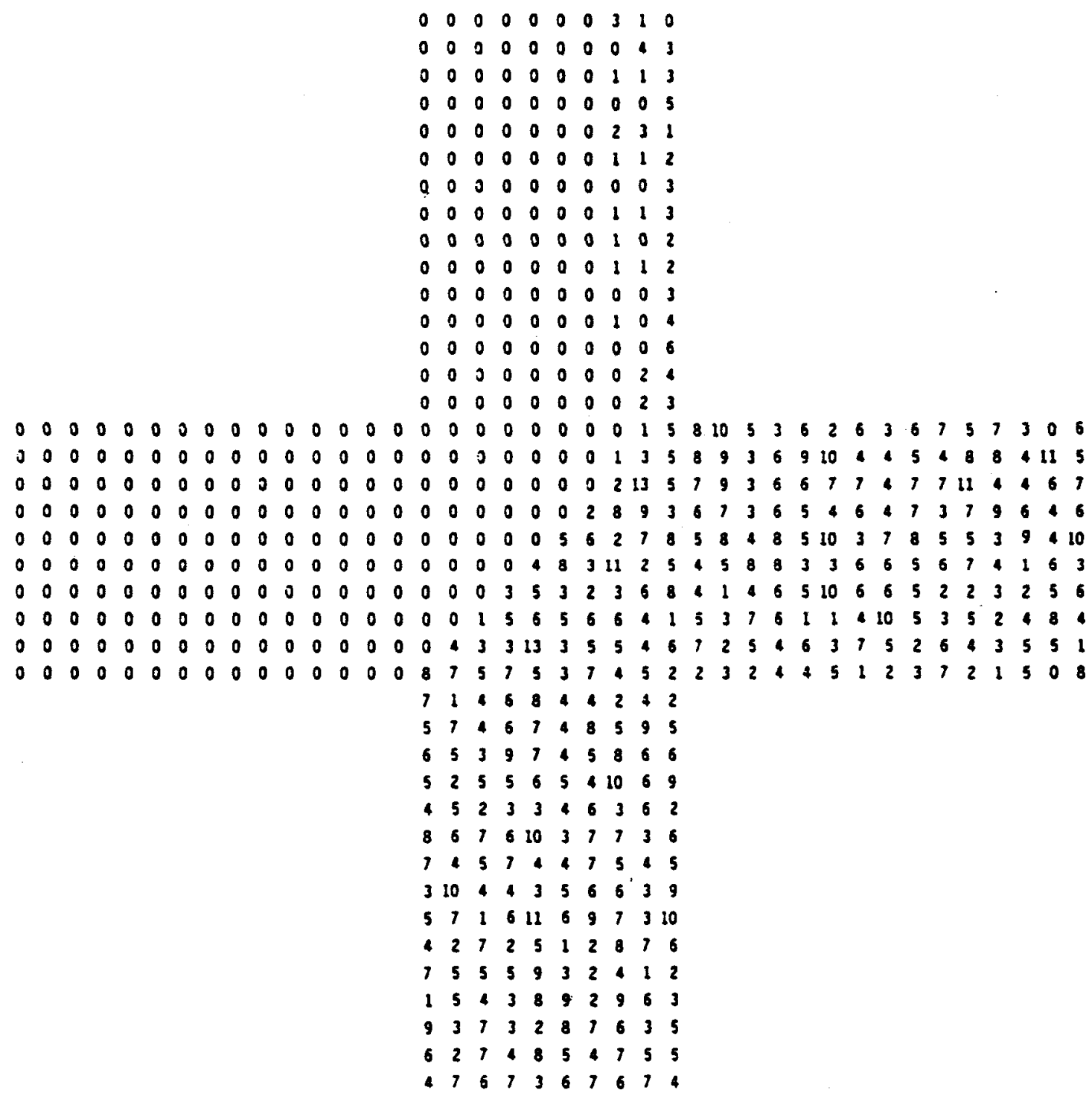

Figure 28. Computer simulation of a fracture junction showing distribution of tracer when inflow from the left equals inflow from the bottom. Average flow velocity is $1 \mathrm{~m} / \mathrm{day}$. The effects of diffusion can be seen by some particles exiting the junction through the upper channel. 
the residence time of the tracer in the junction. This time is related to the diffusion coefficient and the width of the junction by Equation 20 . In this case, however, the boundary conditions are the less rigorous constant mass boundary conditions, and the constant in Equation 20 is not 2.0 but 0.5 . From this constraint on residence time in the fracture junction, the flow rates permissible for junctions of fractures of equal aperture can be calculated. Figure 29 shows a plot of aperture versus flow velocity, with pressure gradients based on the Polseullle velocity equation. The upper limit of fluid velocity that will allow complete mixing of solutions at junctions is superimposed. Estimates of flow rates and gradients from the Columbia River basalts near Hanford, Washington are shown to give some idea of velocities that might be observed in a field situation. Clearly, the conditions under which complete mixing at junctions will occur are limited, and a computer code that assumed complete mixing in its algorithm would cause increased lateral dispersion of tracer, and consequentiy decreased concentration peaks in the direction of flow. 


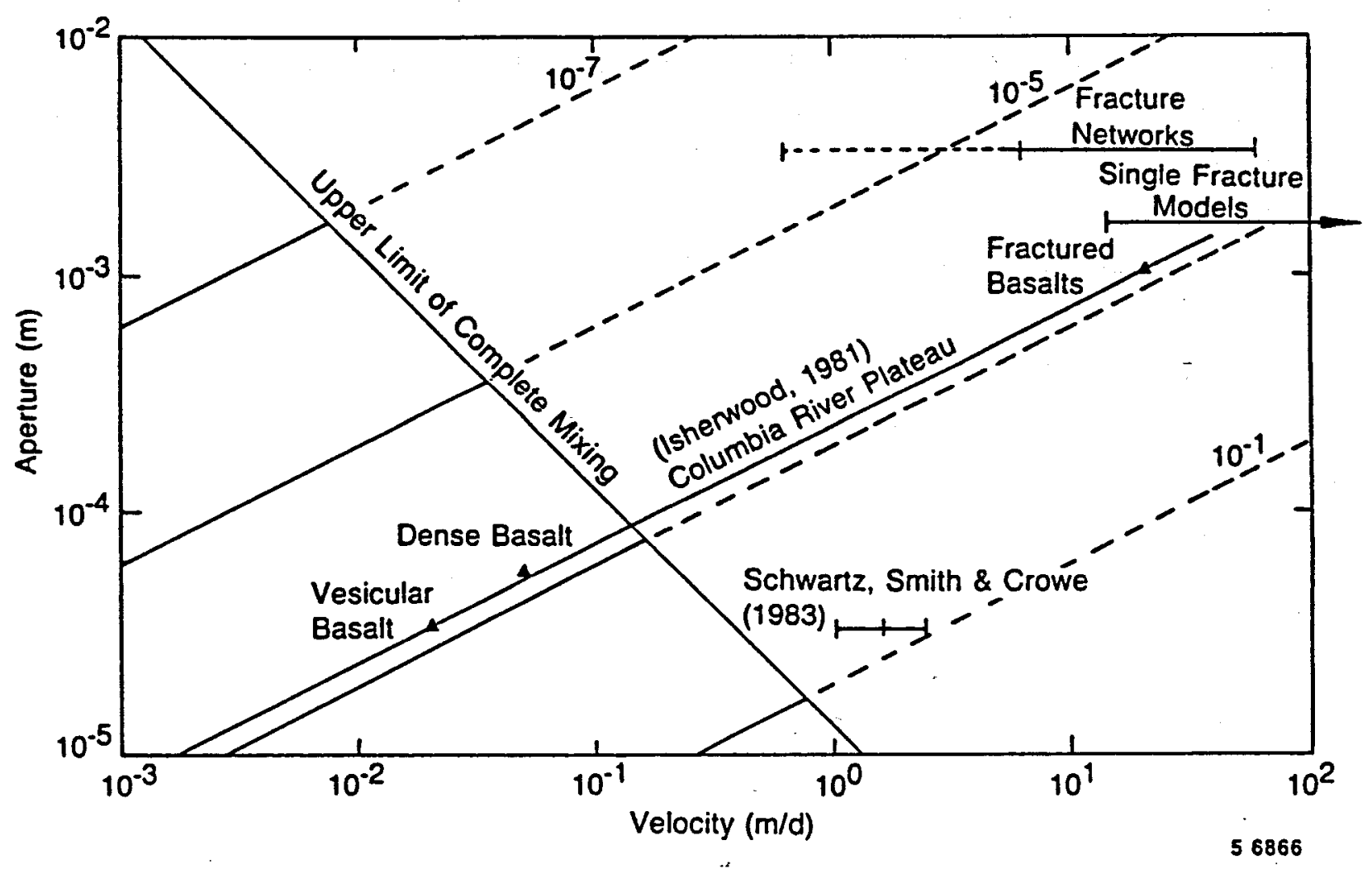

Fijure 29. Maximun velocities in fractures of various apertures that permit sufficient residence time for mixing to occur due to moiecular difiusior. Diagonal lines from lower left to upper right represent ines of constant hydraulic gradient. 


\section{INTERPRETATION OF INJECTION-BACKFLOW}

TRACER RECOVERY CURVES

To aid in the refinement of the injection-backflow technique of well testing, experiments similar to those conducted in the field have been carried out in laboratory-scale fracture networks. The first sequence of fleld tests was conducted at the Raft River geothermal site in south-central Idaho. Numerical simulations of the test results are currently underway using the FRACSL reservoir simulation code. Estimates of reservoir parameters and significant processes discussed here will be further refined and confirmed using more elaborate techniques.

\section{Raft River field Tests}

The Raft River geothermal fleld, located in southern Idaho (Figure 30), includes five deep geothermal production wells, two intermediate depth injection wells, and thirteen monitor wells. Drilling of these wells was completed between 1975 and 1978 during which time numerous tests were run. Data collected indicate that the reservoir is fracture dominated and not amenable to conventional reservoir analysis (Dolenc et al., 1981).

Injection-backflow testing at Raft River was conducted on well RRGP-5 (Figure 30), a $1500 \mathrm{~m}$ deep production well. A major fracture zone with an aperture of 0.3 to $1.5 \mathrm{~m}$ was intercepted during drilling (USOOE, 1980), but was grouted-off to permit casing of the well. When drilling resumed, the grout could not be removed from the fracture zone. Hydrofracturing generated a man-made fracture $1.5 \mathrm{~cm}$ wide and $43 \mathrm{~m}$ long (vertically), that intersects the major fracture zone at some unknown distance from the wellbore (USDOE, 1980). Spinner surveys indicate the existence of one primary producing zone associated with the hydrofracture just below the well casing.

We11 RRGE-3, approximately $2400 \mathrm{~m}$ from the injection well, was chosen as the supply well for injection testing. RRGE-3 fluids contain almost 


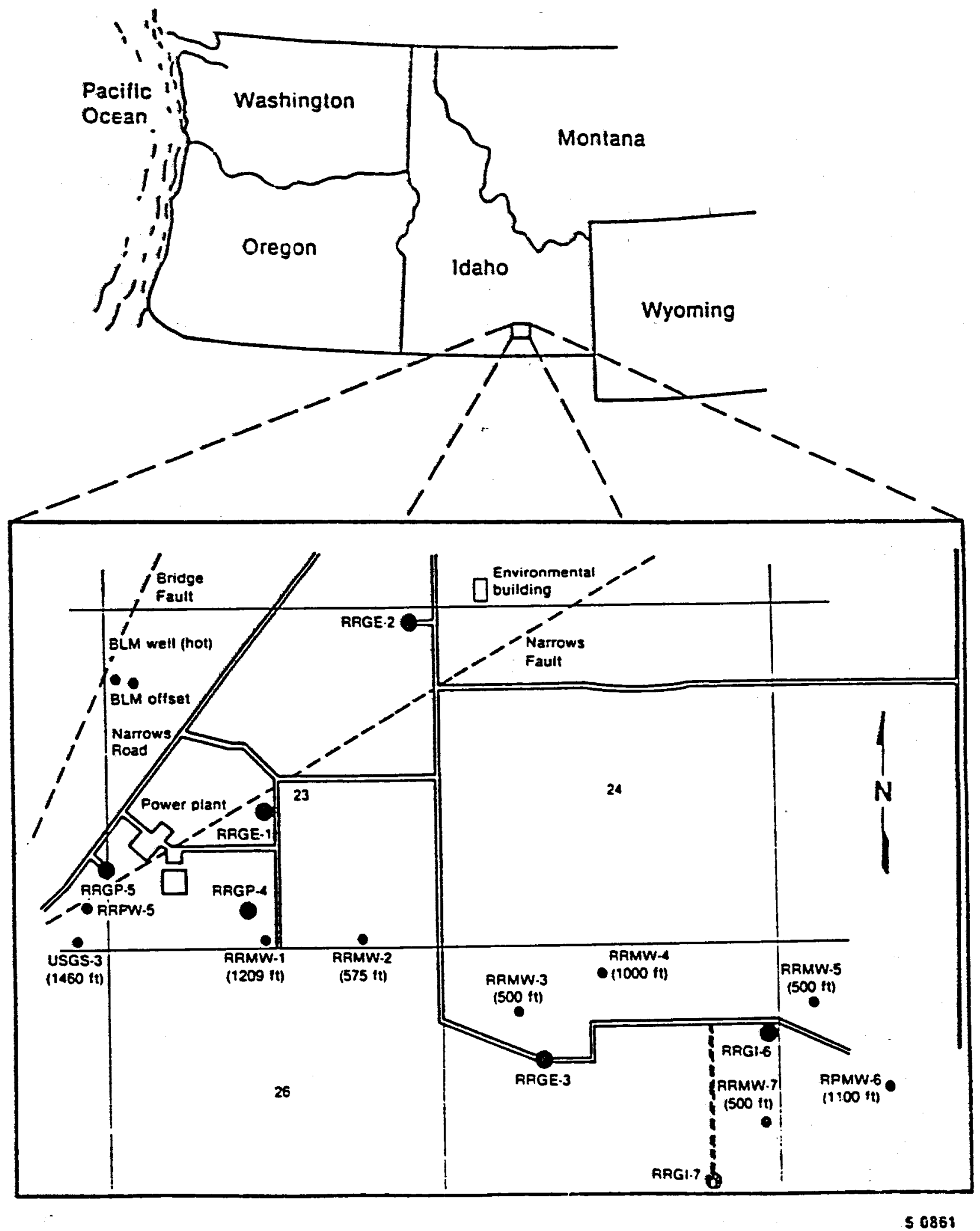

Figure 30. Map showing locations of the Raft River geothermal field and the geothermal wells used in testing. 
twice the sodium and chloride concentrations of we 17 RRGP-5, providing good natural tracers.

Tests conducted at Raft River consisted of injecting a series of increasing fluid volumes to examine greater portions of the reservoir around RRGP-5. A detailed description of the tests may be found in Downs et a 1., (1982) and Capuano et a 1., (1983). The tests were designed to evaluate characteristics of greater reservoir volumes by examining tracer recovery curves from three tests where different volumes of fluid were injected and recovered. Tracer solution volumes of $63 \mathrm{~m}^{3}, 1500 \mathrm{~m}^{3}$, and $3300 \mathrm{~m}^{3}$ were injected during the three tests.

Tracer recovery curves are shown in figure 31 . As the volume of fluid injected increased, the recovery curve spread out over greater time periods, indicating a greater amount of mixing between injected and reservoir fluids. Backflow portions of the recovery curves were normalized by dividing the volume of flutd recovered up to that time by the total volume of fluld injected. The normalized recovery curves (figure 32) were coincident. There therefore appear to be no major changes in reservoir characteristics within the 1 imited range of reservoir tested.

\section{Physical Model Description and Tests}

The physical model used to carry out laboratory tests similar to those conducted in the field consists of a rectangular fracture network. The network consists of or thogonal fractures $0.32 \mathrm{~cm}$ wide and $1.91 \mathrm{~cm}$ deep, cut into a sheet of plexiglass $57 \mathrm{~cm}$ wide and $172 \mathrm{~cm}$ long (Figure 33).

Fracture spacing is a uniform $10.2 \mathrm{~cm}$, and all fractures are continuous and meet the model boundaries at 45 degrees.

Injection-backflow tests of four different volumes were conducted. Injection volumes of $60,120,180$, and $240 \mathrm{~cm}^{3}$ were injected at a constant rate of $20 \mathrm{~cm}^{3} / \mathrm{min}$. The raw data from these four tests is plotted in Figure 34 . The injection time has been subtracted from the time axis, so that backflow began at time $=0$. Similar behavior to the field tests is observed, with the spread in the tracer recovery curves 


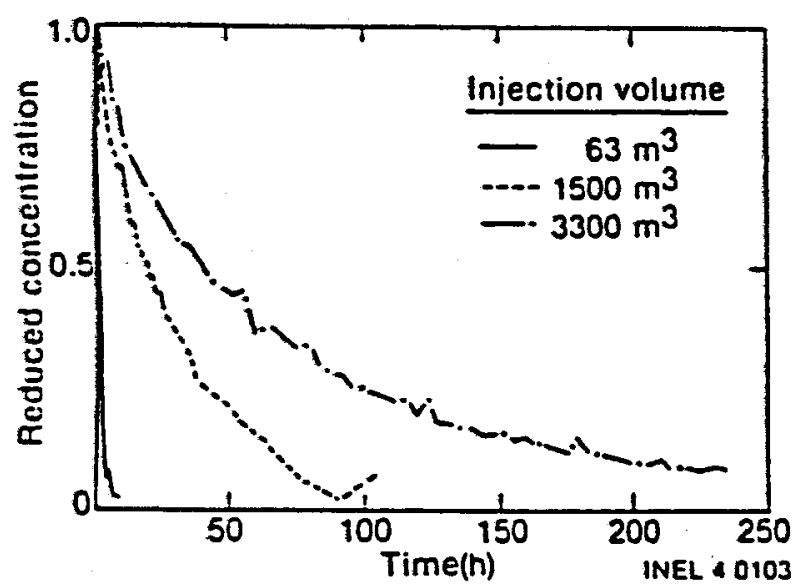

Figure 31. Tracer recovery curves for backflow portions of injection backflow testing in well RRGP-5. Tracer concentrations are normalized to injected tracer concentration.

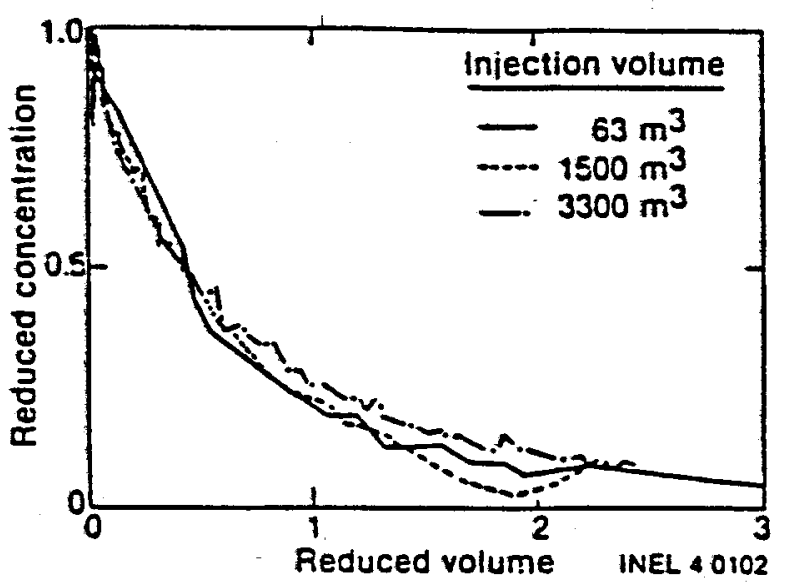

Figure 32. Tracy recovery curves for backflow portions of injectionbackflow testing in we 11 RRGP-5. The volume of fiuid extracted from the well is normalized by dividing by the volume of fluid injected.

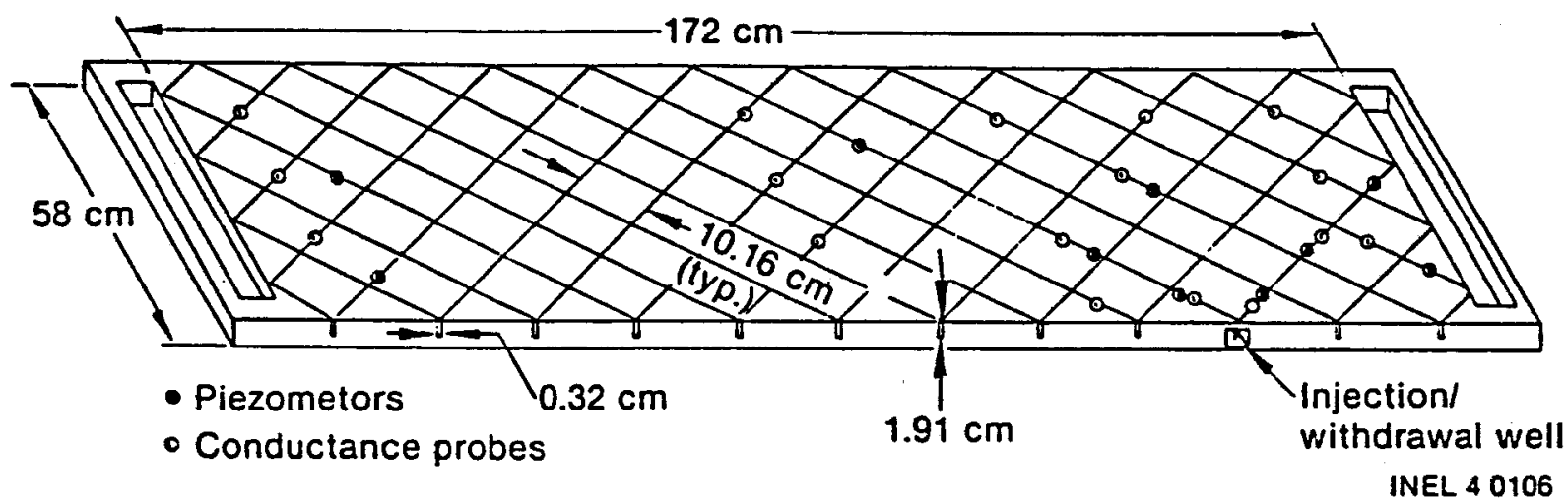

Figure 33. Fracture network used for variable volume injection-backflow tests conducted in the latoratory. 


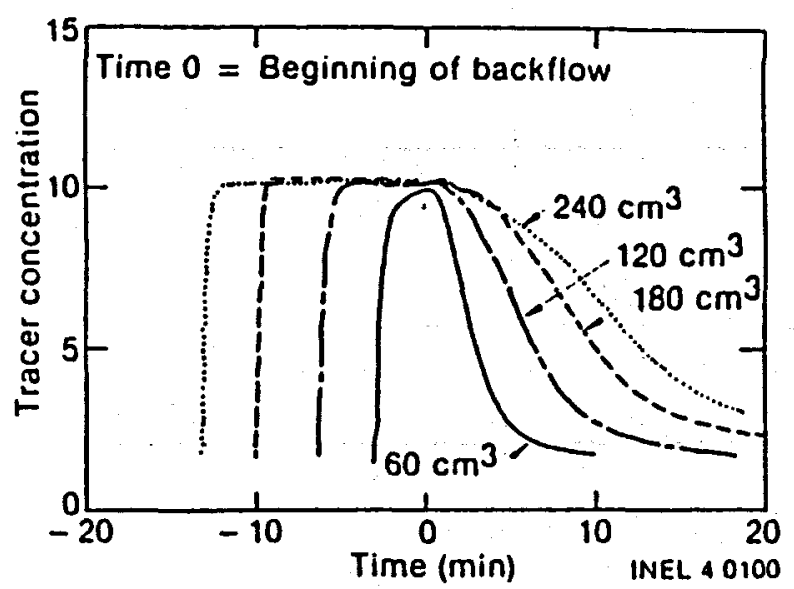

Figure 34. Tracer concentrations for injection-backflow tests conducted in the laboratory fracture network. Injection time has been subtracted from total test duration time.

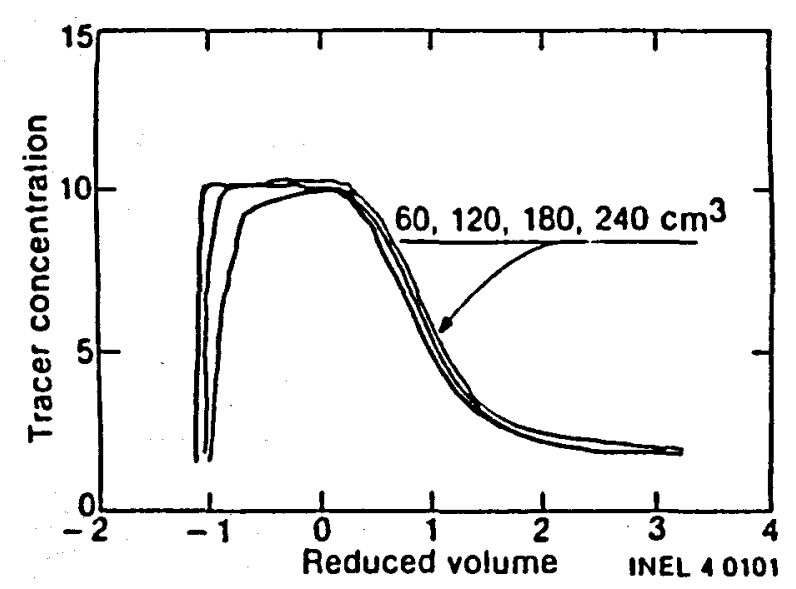

Figure 35. Tracer concentrations for injection-backflow tests conducted in the laboratory fracture network. The volume of fluid extracted is normalized by dividing by the injection volume.

corresponding to greater tracer travel distances in the model. Reducing the recovery curves to relative volume measurement shows that all four curves are coincident (Figure 35).

\section{Comparison of Results}

The behavior of tracer recovery curves from injection into fracture systems at Raft River and in the laboratory model show a general similarity. In both cases, the reduced tracer recovery curves are coincident. Consider what would be expected to happen according to classic dispersion theory. As the volume of fluid injected increased, the tracer front would move further from the wellbore. This would increase the value of the Peclet number $\left(u x / D_{1}\right)$ by increasing the value of $x$. This assumes that there is a constant dispersion coefficient that describes the mixing of the injected and nalive fluids. The effects of increasing the Peclet nimber are 1lliustrated in Figure 36. In Figure 36b, the absolute spread in the tracer front increases with distance travelled. However. Figure $36 \mathrm{c}$ shows that the reduced tracer breakthrough curves become steeper as the peclet number increases. While the spread of the tracer front increases 


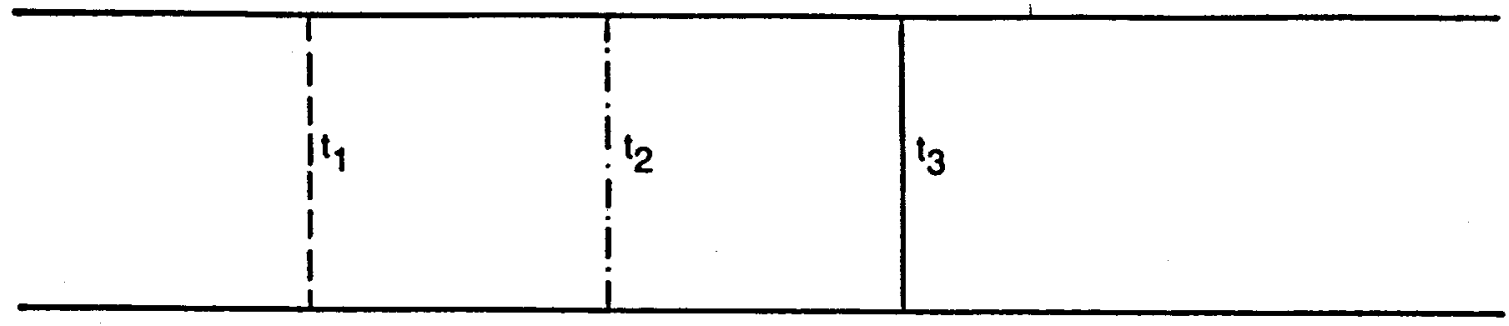

a.
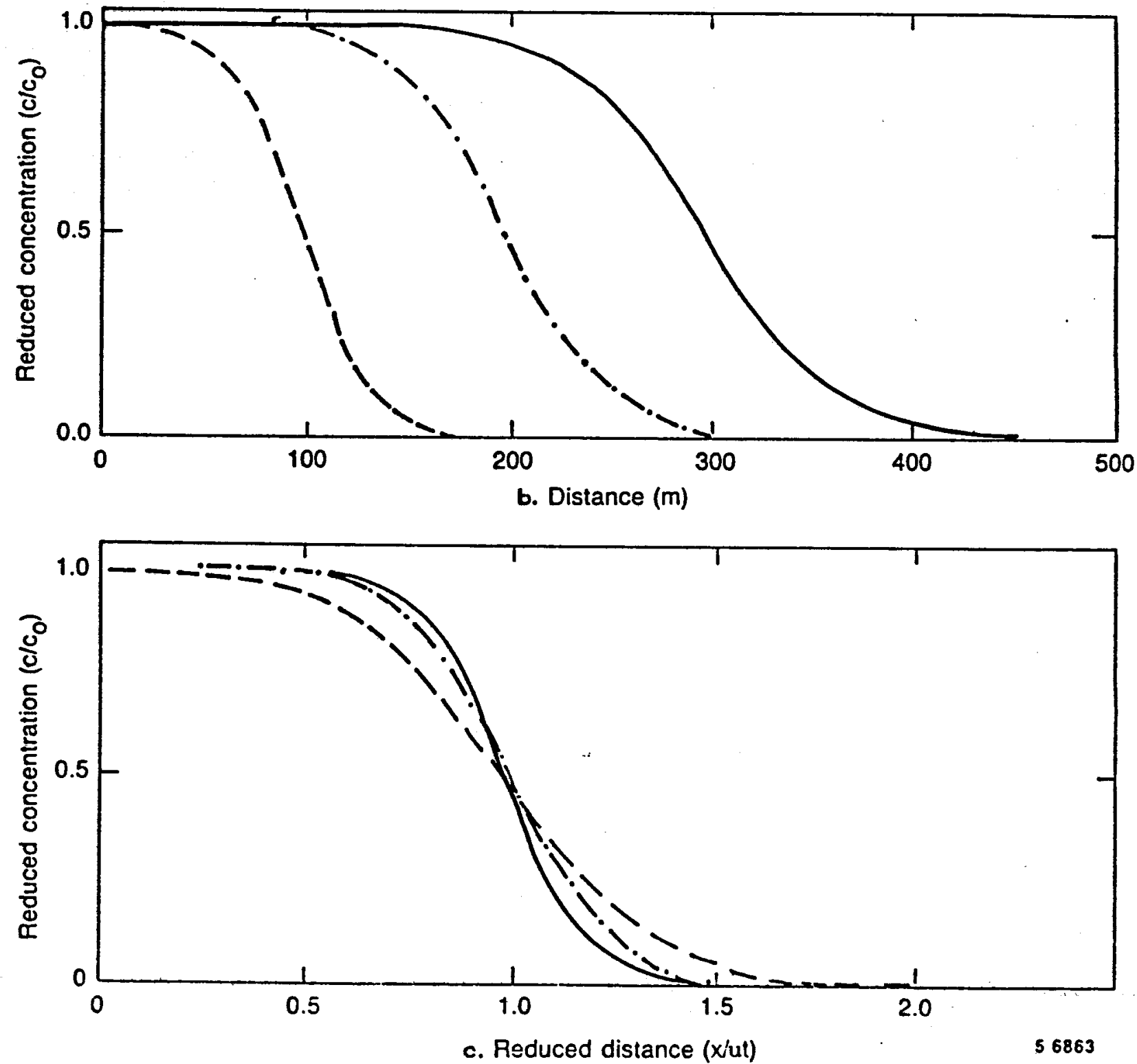

Figures $36 \mathrm{a}, 36 \mathrm{~b}$, and $36 \mathrm{c}$. Changes in shape of a one-dimensional tracer front at various distances from an injection point, tased on classic dispersion theory. 
with distance travelled, the relative spread compared to the total distance travelled decreases.

For the tests conducted in the fracture networks at Raft River and in the laboratory, the reduced tracer recovery curves did not become steeper as the distance the tracer front travelled increased. This indicates that, at least in the classical sense, that the Peclet number remained constant. This requires that the dispersion coefficient also increased. Increasing dispersion coefficients with the distance over which they are measured is commonly observed in measurement of dispersion coeffictents for porous media (Fried, 1975; Smith and Schwartz, 1980). An alternative explanation is avaliable for studies in fractured media.

The coincidence of the reduced tracer recovery curves for the injection-backflow tests conducted in the fracture systems can be explained by the hydrodynamics of flow between parallel plates. When flow rates in fractures are fairly high, classic dispersion theory is not valid, and the classic Peclet number cannot be used in these situations. That velocity profile effects were significant was clearly observed during testing of the laboratory mode1. Stringers of tracer moved rapidiy up the center of fractures, retaining their parabolic shape even when split at junctions. For classic dispersion theory, there is no constraint on the range of fluid velocities encountered, but the range rapidly takes on a Gaussian distribution with distance travelled. For flow in a parallel plate fracture, however, there are definite constraints on the range of fluid velocities encountered. In the center of the fracture, flow will travel 1.5 times the mean velocity (Figure 37 ). Along the fracture walls, the velocity will be zero. This then constrains any tracer to cover a range of fracture between a point of 0 and 1.5 ut (Figure 37c). Normalizing any tracer breakthrough curve will generate a curve that connects these two points, irregardless of the distance the tracer front has travelled.

Naturally, it is not that simple. Transverse diffusion will cause tracer to move between streamilines, and therefore to move at a range of velocities. This will distort the shape of the breakthrough curve, by moving the $C=C_{0}$ point away from the origin of the fracture, and slowing 

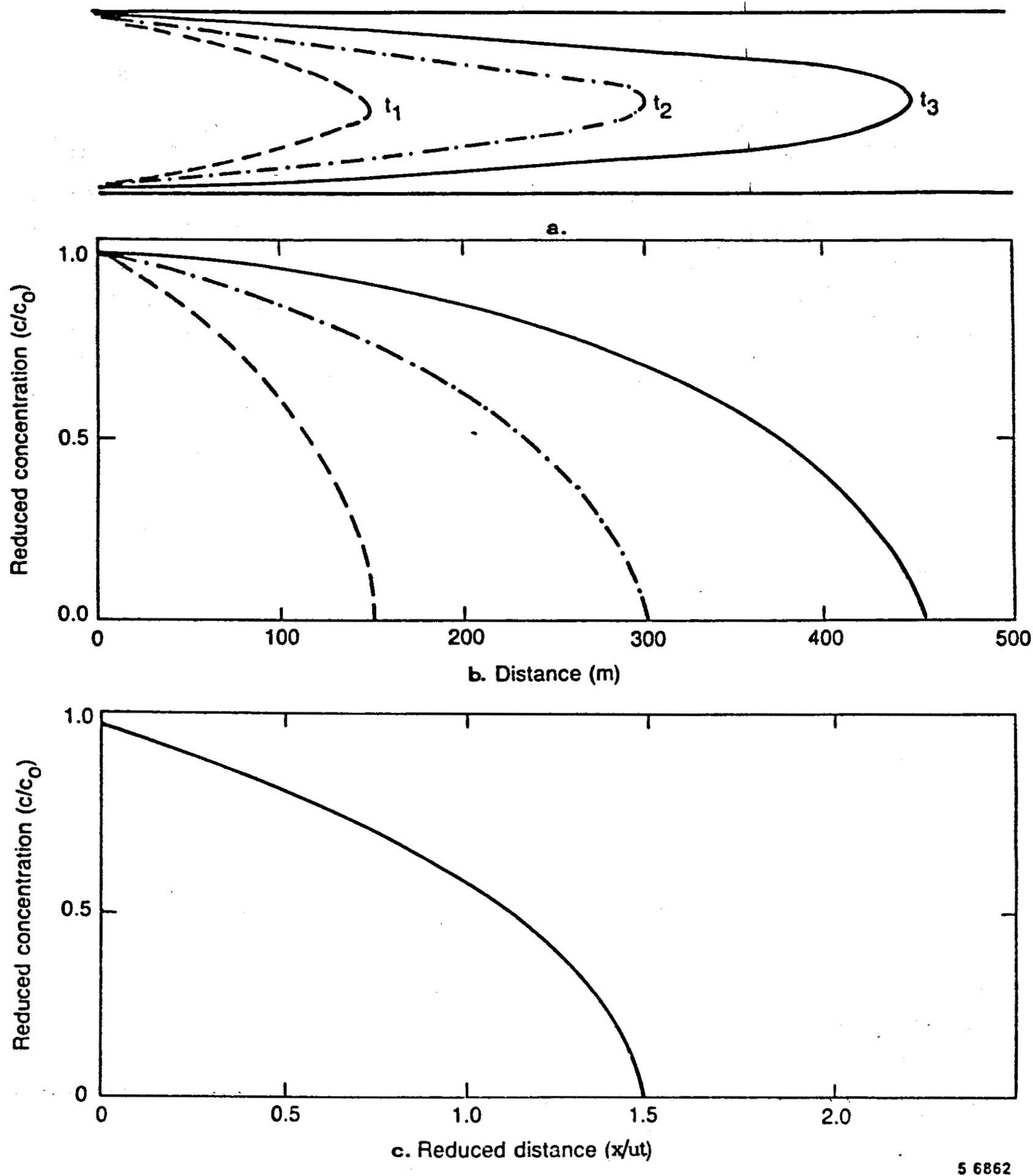

Figures 37a, 37b, 37c. Clianges in shape of a tracer front moving betwcen infinite parallel plates at varlous distances from an injection point. Transverse diffusion is assumed to be negligible. 
the peak velocity to less than $1.5 \mathrm{u}$. At the extreme, diffusion will homogenize the tracer, under which conditions, classic dispersion theory will be applicable to the fracture system. In the complete absence of diffusion, the recovery curve from an injection-backflow test would be a mirror image of the injection portion, with no spread in the data.

The shape of the recovery curve, therefore represents the interaction of the distribution of flow velocity in the fracture with transverse diffusion homogenizing the tracer concentration. Thus, the tracer recovery curves from a series of tests can be used to estimate the fracture aperture based on an assumed geometry of the fracture. For diffusion to homogenize tracer within a fracture requires a dimensionless time of $\mathbf{2 . 0}$ (Equation 20). Based on measured apertures of the major fracture zone at Raft River of 0.3 to 1.5 meters gives homogenization times of 52 to 1300 days. Thus, homogenization would not be expected to have occurred during the tests conducted at Raft River. Lengths of tests to be conducted for future injection-backflow field experiments can be calculated from estimates of fracture aperture from downhole measurements and Equation 20. A range of tests covering dimensionless times of 1.0 to 3.0 would provide sensitivity in estimating fracture apertures.

Results from the Raft River field site provide an example of dispersion within single fractures producing important effects in tracer breakthrough. Ignoring the effects of microdispersion would make interpretation of these test results difficult. Also, the Raft River resuits provide a field example where parallel plate theory provides a good explanation of observed behavior of a natural fracture system. 
While transport of solutes through fractures is important, most fracture systems occur in rocks where the rock has some permeability and porosity. This so-called matrix porosity will greatly affect the transport of solutes and heat transfer in a geothermal reservoir. A number of laboratory studies have recorded significant effects of diffusion of solutes from fractures into matrix material (Grisak and Pickens, 1980; Grisak et a1., 1980; Neretnieks et a1., 1982). The general approach to solving dual porosity systems is to ignore flow in the matrix blocks, and to treat heat and mass transfer between blocks and matr $\{x$ as a one-dimensional diffusion process. This approach is based on the assumption that pressure gradients across matrix blocks in a dual porosity fracture network are trivial compared to pressure gradients between blocks and fractures.

This assumption may be true for continuous fracture systems in low permeability matrix materials, but not for systems with deadend fractures or in rocks with high matrix permeability. An example of this type of situation would be where major fractures and faults were being simulated discretely, and the remaining fractures were lumped together into a continuum, and treated as matrix. Very significant pressure gradients can develop across matrix blocks that lie between deadend fractures. Diffusion is not the only process for transferring material from fractures to matrix and vice versa. Advection can play an important role. Therefore, a laboratory scale model of a dual permeability fracture network has been designed, and is currently being constructed.

\section{Mode 1 Design and Construction}

The dual permeablitity fracture model should allow for both fractures and porous matrix blocks that participate in the flow system. A broad range of materials were considered including corundum, sintered glass, scintered metal, glass and plastic beads, natural rocks, porous ceramic, and porous polyethylene. Porous ceramic was the first material of choice because it was hyraulically well characterized, and could be fractured to 
produce 'natural' fractures. The ceramic could be made in sheets of $30.5 \times 30.5 \times 1.25 \mathrm{~cm}$ on a custom order basis. Standard materials were only $0.67 \mathrm{~cm}$ thick. In making the sheets of ceramic, a double pour process was used, which left a zone of high permeability down the center of the porous ceramic plates. This was unacceptable for use in a physical model. A second shortcomming of the porous ceramic was its extremely low permeability, on the order of $10^{-7} \mathrm{~cm} / \mathrm{min}$. Little flow would have entered the matrix under achievable pressure gradients. If single pour plates can be made, the material may have some future use. With its high porosity (50\%) and low permeability, it would make a good surrogate shale.

The second material selected was a porous polyethylene. It is available in sheets $1 \mathrm{~m}$ by $1 \mathrm{~m}$ by $2 \mathrm{~cm}$ thick with a pore size of 40 microns. This material could not be fractured to create 'natural' fractures, but could be machined easily. This allowed a much more elaborate fracture network to be designed, one that included deadend fractures. The porous polyethelene is somewhat like a sandstone in properties, it has a porosity of $35 \%$ and an estimated permeability of $0.20 \mathrm{~cm} / \mathrm{min}$. A fracture network has been designed (Figure 38 ) and the pieces have been cut. Tolerances in the machining are \pm 125 microns. Fracture apertures range from 380 to 1500 microns, and are lognormally distributed.

A small matrix block model has been constructed for testing of sealing materials and for measurement of hydraulic and dispersivity characteristics of the porous polyethelene. The block is $15.25 \mathrm{~cm}$ long and $10.2 \mathrm{~cm}$ wide. Manifolds on two sides give constant head boundaries to control flow through the block. Flow tests have been conducted where pressure drop and flow rate were measured. The hydraulic conductivity of the porous polyethelene was then calculated from Darcy's Law: 


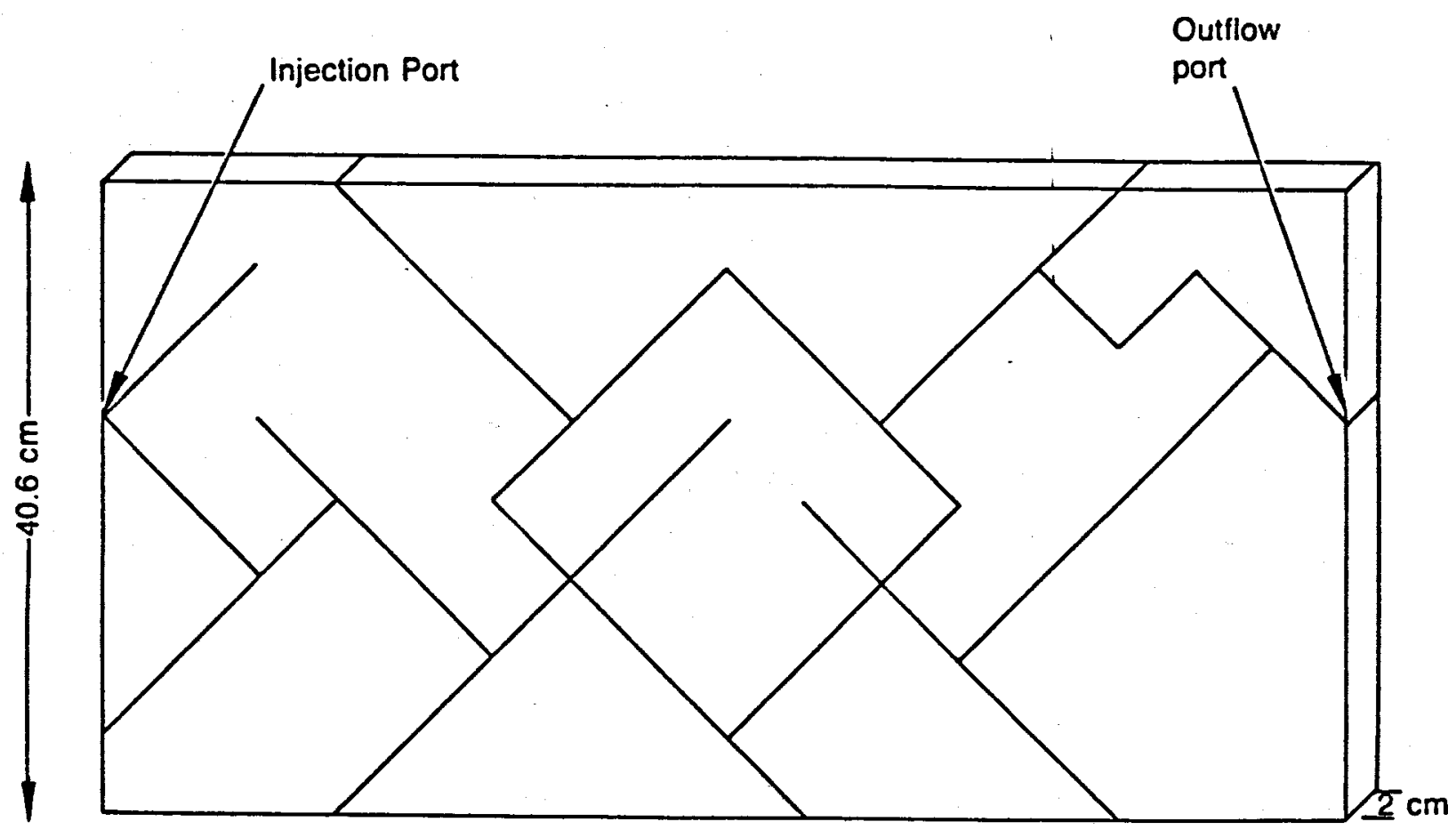

$81.3 \mathrm{~cm}$

56867

Figure 38. Schematic of the dual-permeability fracture network mode1.

$Q / A=K d h / d x$

where

$Q=$ volumetric flow rate

$A=$ area for flow, $30.5 \mathrm{~cm}^{2}$

$K=$ hydraulic conductivity

$d h / d x=$ hydraulte gradient .

Electrodes have been installed in the block, and mini-tracer tests conducter. Normaiized tracer concentrations are plotted against a volume 
modifying function on probability paper (Brigham, 1974), and the variance determined from the plot used to calculate the dispersion coefficient. The volume modifying function (U) is calculated from:

$U=\frac{u t / x-1}{\sqrt{u t / x}}$

Figure 39 shows a plot of reduced tracer concentration versus $U$ for a tracer breakthrough curve calculated using Equation 7 with a Peclet number of 100 . The plot is ilnear despite the fact that there are significant effects from the product of the exponential and error function terms in Equation 7. The Peclet number is related to the slope of the plot by:

$\mathrm{Pe}=\left(\frac{2.380}{\mathrm{U}_{80}-\mathrm{U}_{20}}\right)^{2}=\left(\frac{3.625}{\mathrm{U}_{90}-\mathrm{U}_{10}}\right)^{2}=\left(\frac{4.650}{U_{95}-\mathrm{J}_{5}}\right)^{2}$

From the results of these tests, a dispersivity coefficient of the porous polyethylene will be calculated. The hydraulic conductivity and dispersivity of the matrix material must be determined independentiy before computer simulations of the model can be made. Preliminary computer simulations are being made for design purposes based on estimated parameters.

The fracture network model has been designed so that laminar flow is preserved in all fractures. Calculations to determine the constraints on possible flow velocities in the model were performed using the criteria that the Reynolds number must be less than 2000 for laminar flow (Albertson et a1., 1960). The Reynolds number is defined as:

$R_{e}=\frac{\text { end }}{\mu}$ 


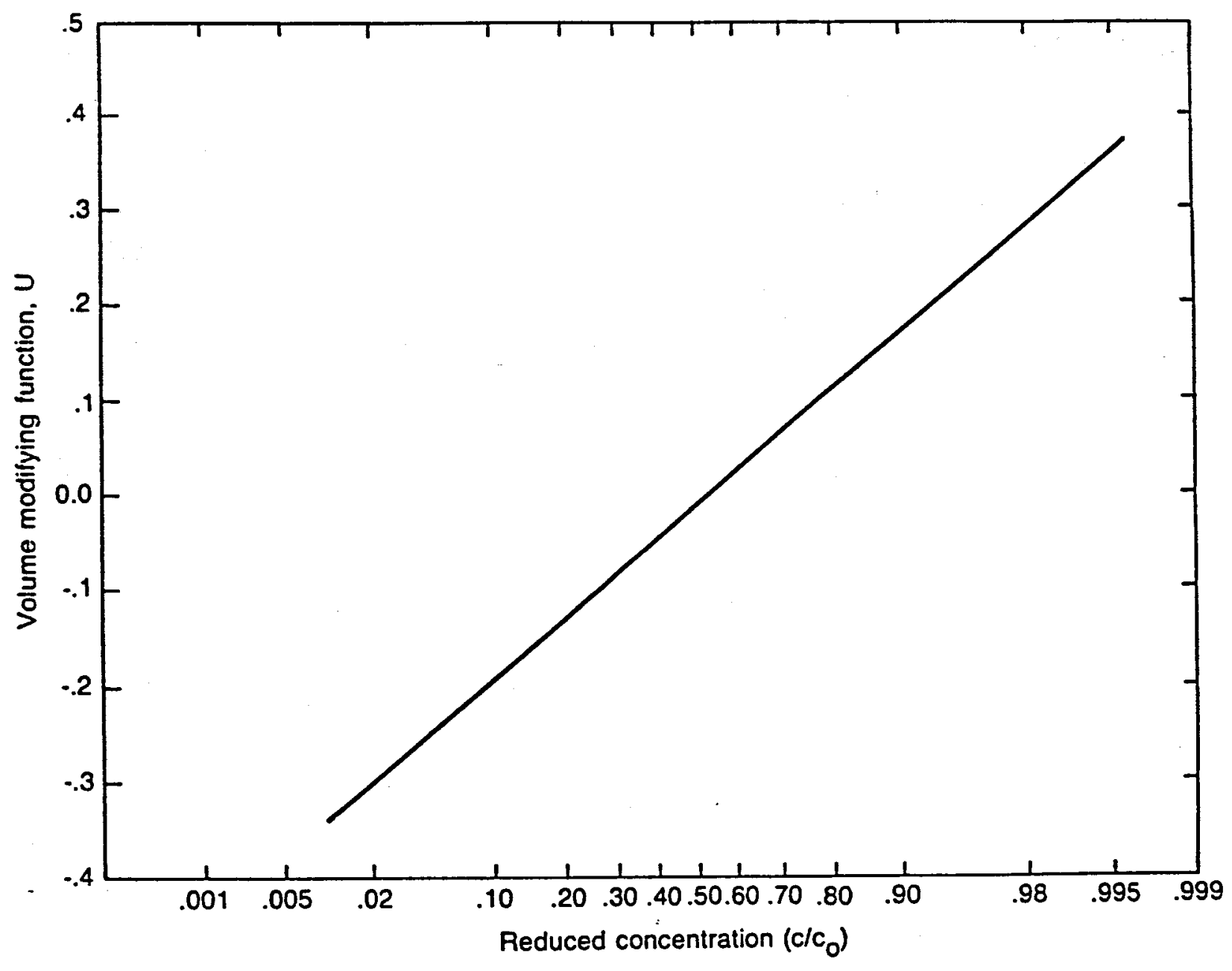

56864

?igure 39. Plot of reduced tracer concentration versus the volume modifying function on probability paper lilustrating the method of determining the dispersion coefficient from the test data. 
where

d = diameter of the circular pipe

$p \quad=$ fluid density

$\mu \quad=$ fluid viscosity

This equation for circular pipes can be used for rectangular channels by replacing diameter with the equivalent hydraulic radius (Albertson et a1.. 1960). The hydraulic radius $\left(H_{r}\right)$ is the cross sectional area of the conduit divided by the perimeter (p).

$H_{r}=\frac{A}{P}$

For circular pipes, the hydraulic radius is the diameter (d) divided by 4. Therefore, the hydraulic radius of the rectangular channel multiplied by 4 is used to replace $d$ in Equation 48.

Design criteria for the model are $b=190$ microns and $z=2 \mathrm{~cm}$. Using density and viscosity data for water at $20^{\circ} \mathrm{C}$ and the criteria that the Reynolds number be less than 2000, a maximum velocity permissible in the fractures can be calculated. For a fracture hydraulic radius of $0.019 \mathrm{~cm}$, the maximum velocity allowable to retain laminar flow is $270 \mathrm{~cm} / \mathrm{sec}$. This velocity is much higher than any planned for use in the model.

Representative velocities for the model calculated using the FRACSL code are on the order of 0.1 to $5 \mathrm{~cm} / \mathrm{sec}$.

Electrodes and piezometers will be installed in the model, both in fractures and in matrix blocks, to monitor pressure and movement of tracer solutions. FRACSL simulations of the model are being conducted prior to installation, so that monitoring instruments can be placed in the best locations. 
The dual-permeability model shown in Figure 38 has been simulated using estimated parameters and the indicated dimensions. Figure 40 shows the predicted pressure distribution within the model under steady-state conditions. The fluid will be injected at point $A$ and withdrawn at point $B$. The slope in the pressure gradient is not uniform from inlet to outlet, but shows some very steep discontinulties, the most prominent of which is between points $C$ and $D$. This steep pressure gradient develops between two deadend fractures, which end close to each other, but are connected to the fracture network at very different locations. Thus, there is a very steep pressure gradient to drive solutes into the matrix between these two fractures. Figure 41 is a map view of the fracture network, somewhat distorted, and shows position of tracer solution, injected as a 5 minute slug, after 60 minutes of moving through the fracture network. Tracer has moved into the matrix in a number of locations. After longer times, tracer will connect to other fractures, and move out of the matrix into new fractures, and then back into the connected fracture system. This model design provides a number of very rigorous tests to assess the capabilities of a fracture network simulation code. 


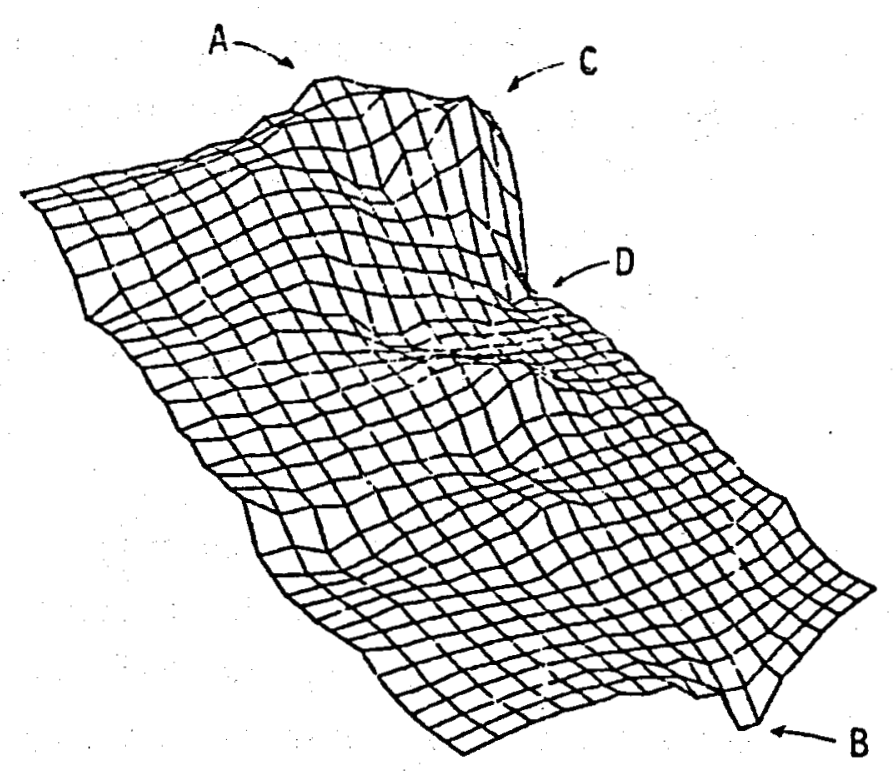

Figure 40. Predicted steady-state pressure distribution in the dualpermeability laboratory model using the FRACSL code.

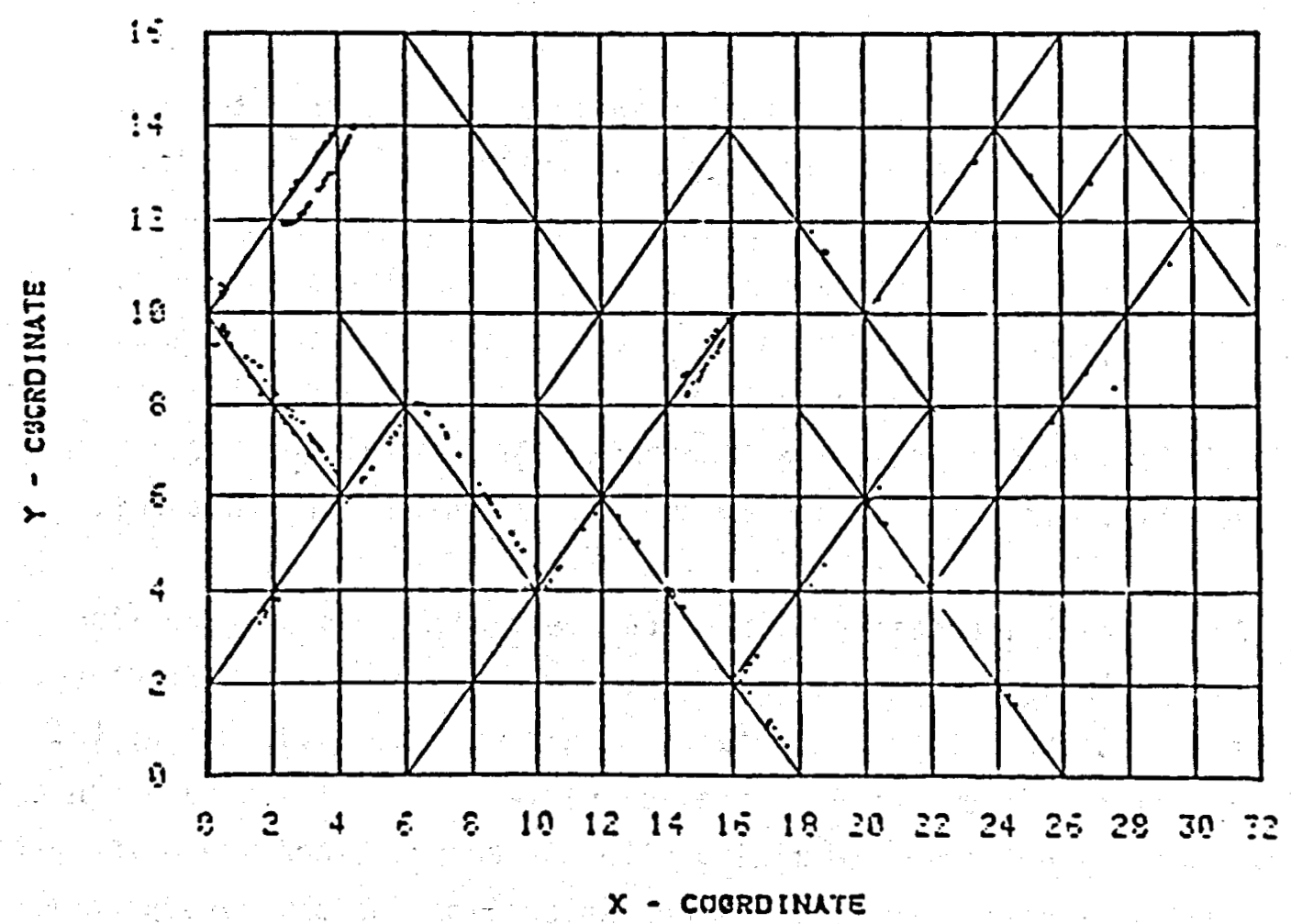

Figure 41. Predicted tracer distribution in the dual-permeability laboratory model using the FRACSL code. 
Physical models provide a means for studying the dispersion phenomenon in fractures under controlied conditions, where observation can heip increase the understanding of the transport processes. They also provide a means of validating computer codes that simulate flow and transport in fracture networks. While the conditions represented by the physical models are not necessarily realistic, the processes involved must be properly handled to successfully match lab data.

Particle tracking algorithms for simulating transport have been validated using analytical solutions and single fracture and single fracture function physical mode1s. Particle tracking has the advantages that it is not susceptable to numerical dispersion or oscillation, and can readily handle a range of Peclet numbers. It also is readily adaptable to calculating advective or dispersive transfer between fractures and matrix blocks. The same type of algortthm is also adaptable to calculating heat transfer.

Laboratory and computer simulation studies were used to study conceptual models of solute transport in fractures. At low flow rates, transverse diffusion between streamilines in a fracture homogenizes tracer concentrations. Under these conditions, the one-dimensional advection dispersion equation can be used to describe transport in a fracture. As flow rates increase, homogenization does not occur, and a two-dimensional approach is needed to describe transport. The conditions under which each approach is valid is described by the Peclet number for fractures.

An apparent increasing dispersion coefficient was observed for injection both into the fractured geothermal reservoir at Raft River, and into the laboratory fracture network. This can be explained by the hydrodynamics of flow between parallel plates. This illustrates an example where there is not complete mixing within fractures, and where the parallel plate model of fractures provides an explanation for observed phenomenon. 
A dual permeability fracture network model is being bullt in the lab. The model demonstrates the importance of deadend fractures in controlling the migration of solutes into matrix blocks. Tests will be conducted on a small block of matrix material to obtain independent measurements of hydraulic conductivity and dispersivity for use in a numerical simulation using FRACSL. Preliminary FRACSL runs are being used to locate electrodes and piezometers for maximum information. 


\section{ACKNOWLEDGEMENTS}

The author would like to thank C. C. Chenoweth and J. R. Lord for their perseverance in the laboratory, and for making things work; $K$. N. Koslow for helping in designing and conducting the laboratory experiments, and for helpful discussions on what dispersion really is: T. M. Clemo for assistance on the derivations and, along with J. D. Miller, for aid in making the computer simulations using FRACSL. Funding for this study was provided by the U. S. Department of Energy under contract number DE-AC07-76I001570. 


\section{REFERENCES}

Abelin, H., J. Gidlund, and I. Neretnieks, 1982, Migration in a Single Fracture, Scientific Basis for Nuclear Waste Management, V. Vo1. 11,

Elsevier Science Publishing Co., Inc., NY, pp. 529-538.

Ahlstrom, S. W., H. P. Foote, R. C. Arnett, C. R. Cole, and R. J. Serne, 1977, Multicomponent Mass Transport Mode 1: Theory and Numerical

Implementation (Discrete-Partic le-Random-Walk Version), BNWL-2127, Pacific Nor thwest Laboratory, Richland. WA.

Albertson, M. L., J. R. Barton, and D. B. Simons, 1960, Fluid Mechanics for Engineers, Prentice-Ha11, Inc., Englewood Cliffs, NJ.

Amsden, A. A., H. M. Ruppe1, and C. H. Hirt, 1980, SALE: A Simplified ALE Computer Program for Fluid Flow at All Speeds, LA-8095 VC-32, Los Alamos National Laboratory, Los Alamos, NH.

Baca, R. G., R. C. Arnett, and I. P. King, 1981, Numerical Modeling of Flow and Transport Processes in a Fractured-Porous Rock System, RHO-BWI-SA-113, Rockwe 11 Hanford Operations, Hanford, WA.

Bear, Jacob, 1972, Dynamics of Fluids in Porous Media. American Elsevier Publishing Co., NY, pp. 579-663.

Brigham, W. E., 1974, Mixing Equations in Short Laboratory Cores, Society of Petroleum Engineers Journa1, pp. 97-99.

Capuano, R. M., M. C. Adams, and P. M. Wright, 1983, Tracer Recovery and Mixing from Two Geothermal Injection-Backflow Studies, Ninth Annual Stanford Geothermal Reservoir Engineering Conference, SGP-TR-74, Stanford University, Pp. 299-304.

Clemo, T. M., and J. D. Miller, 1984, Simulation of Flow and Dispersion in the East Mesa Reservoir, SE-PB-84-056, EG\&G Idaho, Inc., Idaho Fa11s, ID.

Crank, J., 1975, The Mathematics of Diffusion, Oxford University Press, London.

Dolenc, M. R., et a1.. 1981, Raft River Geosciences Case Study, EGG-2125, EG\&G Idaho, Inc., Idaho Fal1s, IO.

Downs, H. F., R. E. McAtee, R. M. Capuano, and H. S111, 1982, Hydrothermal Injection Experiments at the Raft River KGRA, Idaho, Eight Annual Stanford Geothermal Reservoir. Engineering Conference, SGP-TR-60, Stanford University, Pp. 275-278.

Endo, H. K., 1984, Mechanical Transport in Two-Dimensional Networks of Fractures, LBL-17491, Lawerence Berkeley Laboratory, Berkeley, CA.

Fossum, M. P., and R. N. Horne, 1982, Interpretation of Tracer Return Profiles at Wairakef Geothermai Ffeld Using Fracture Analysis, Geothermal Resources Counci1, Transactions, $\underline{6}$. 
Fried, J. J., 1975, Groundwater Pollution, Elsevier Science Publishing Co., Inc., NY.

Happe 1, J., and H. Brenner, 1965, Low Reynolds Number Hydrodynamics, Prentice-Hall Inc., Englewood Cliffs, NJ.

Horne, R. N., 1982, Geothermal Reinjection Experience in Japan, Journal of Petroleum Technology, 34, Pp. 495-503.

Horne, R. N. and F. Rodriguez, 1981, Dispersion in Tracer Flow in Fractured Geothermal Systems, Seventh Stanford Geothermal Reservoir Engineering Conference, Stanford University, CA.

Hu11, L. C. and K. N. Koslow, 1982, Dispersion in Fracture Networks, Eighth Stanford Geothermal Reservoir Engineering Conference, SGP-TR-74, Stanford University, CA, Pp. 285-288.

Huyakorn, P. S., 1982, FTRANS, A Two-Dimensional Code for Simulating Fluid Flow and Transport of Radioactive Nuclides in Fractured Rock for Repository Assessment, ONWI/E512-02900/CD-17, Battelle Office of Nuclear Waste Isolation, Columbus, $\mathrm{OH}$.

Isherwood, Dana, 1981, Geosclence Data Base Handbook for Modeling a Nuclear Waste Repository, Vo1. 1 and 2., NUREG/CR-0912, U.S. Nuclear Regulatory Commission.

Krizek, R. J., G. M. Karadi, and E. Socias, 1972, Dispersion of a Contaminant in Fissured Rock. Symposium on Percoiation Through Fissured Rock, Stuttgart, Germany, pp. 1-14.

Mckinley, I. G. and J. M. Hest, 1982, Radionuclide Retardation During Transport Through Fractured Granite, Scientific Basis for Nuclear Waste Management, $Y$, Vol. 11, Elsevier Science Publishing Co., Inc., NY. pp. $811-820$.

Miller, J. D, 1983, Fundamental Approach to the Simulation of Flow and Dispersion in Fractured Media, Ninth Stanford Geothermal Reservoir Engineer ing Conference, SGP-TR-74, Stanford University, CA, PP. 373-379.

Mitchell and Gauthier Assoc., 1981, Advanced Continuous Simulation Language (ACSL) Users Guide and Reference Manual, Mitchell and Gauthier Assoc., P.O. Box 685, Concord, MA.

Neretnieks, Ivars, 1979, Analysis of Some Tracer Runs in Granitic Rock Using a Fissure Model, Sclentific Basis for Nuclear Waste Management. Vo1. 1, Plenum Press, NY, Pp. 417-415.

Neretnieks, Ivars, 1981, Some Difficulties in Interpreting In-Situ Tracer Tests, Sclentific Basis for Nuclear. Waste Management, Vo1. 3, Plenum Press, NY, pp. 473-482.

Neretnieks, Ivars, 1983, A Note on Fracture Flow Dispersion Mechanisms in the Ground, Water Resources Research, 19, pp. 364-370. 
Neretnieks, I., T. Eriksen, and P. Tahtinen, 1982, Tracer Movement in a Single Fissure in Granitic Rock: Some Experimental Results and Their Interpretation, Water Resources Research, 18, Pp. 849-858.

Neuz11, C. E., and J. V. Tracy, 1981, Flow Through Fractures, Water Resources Research, 17, pp. 191-199.

Noorishad, J., and M. Mehran, 1982, An Upstream Finite Element Method for Solution of the Transient Transport Equation in Fractured Porous Media. Water Resources Research, 18, pp. 588-596.

Nutta11, H. E., and A. K. Ray, 1981, A Combined Fractured/Porous Media Model for Contaminant Transport of Radioactive Ions, Scientific Basis for Nuclear Waste Management, Vol. 3, Plenum Press, NY, pp. 577-590.

Ogata, Akio, and R. B. Banks, 1961, A Solution of the Differential Equation of Longitudinal Dispersion in Porous Media, Professional Paper 411-A, U.S. Geological Survey, Reston, VA, PP. A1-A7.

Prickett, T. A., T. G. Naymik, and C. G. Lonnquist, 1981, A 'Random-Halk' Solute Transport Model for Selected Groundwater Quality Evaluations, Bulletin 65, Ilitinois State Water Survey, Champaign, Il.

Rundberg, R. L., J. L. Thompson, and S. Maestas, 1982, Radionucilide Migration: Laboratory Experiments with Isolated Fractures. Scientific Basis for Nuclear Waste Management, Vol. 6, Elsevier Science Publishing Co., Inc., NY, Pp. 239-248.

Russe11, B.F., L. C. Hu11, and W. F. Downs, 1983, Response of East Hesa and Raft River Reservoirs to Injection-Backflow Testing, Ninth Stanford Geothermal Reservoir Engineering Conference, SGP-TR-74, Stanford University, CA, pp. 311-316.

Schwartz, F. W., L. Smith, and A. S. Crowe, 1982, Stochastic Analysis of Groundwater Flow and Contaminant Transport in a Fractured Rock System, Scientific Basis for Nuclear Waste Management, Vol. 6, Elsevier Science Publishing Co., Inc., NY, Pp. 457-463.

Schwartz, F. W., L. Smith, and A. S. Crowe, 1983, A Stochastic Analysis of Macroscopic Dispersion in Fractured Media, Water Resources Research, 19. pp. 1253-1265.

Smith, Leslie, and F. W. Schwartz, 1980, Mass Transport I. A Stochastic Analysis of Microscopic Dispersion, Water Resources Research, 16. pp. 303-313.

Snow, D. T., 1970, The Frequency and Apertures of Fractures in Rock, Int. Journal of Rock Mech. and Min. Sciences, I. Pp. 23-40.

Tang, D. H., E. O. Frind, and E. A. Sudicky, 1981, Contaminant Transport in Fractured Porous Media: Analytical Solution for a Single Fracture. Water Resources Research, 17. pp. 555-564. 
Taylor, G., 1953, Dispersion of Soluble Matter in Solvent Flowing Slowly Through a Tube, Proc. of the Royal Society of London, Series A, 219. pp. 186-203.

Taylor, G., 1954, Conditions Under Which Dispersion of a Solute in a Stream of Solvent Can Be Used to Measure Molecular Diffusion. Proc. of the Royal Society of London, Series A, 225, pp. 473-477.

Travis, B. J., 1984, TRACR3D: A Model of Flow and Transport in Porous/Fractured Media, LA-9667-MS, Los Alamos National Laboratory, Los Alamos, NM.

Travis, B. J., and H. E. Nutta11, 1982, A Comparative Analysis of Fractured and Porous Medium Radionuclide Transport, Scientific Bas is for Nuclear

Waste Management, $\underline{V}$. Elsevier Science Publishing Co., Inc., NY, Pp. 821-830.

U.S. Department of Energy, 1980, Raft River Well Stimulation Experiments, DOE/AL/10563-17, U.S. Department of Energy, Idaho Operations Office. Idaho Falls, ID.

Wilson, C. R., and P. A. Witherspoon, 1976, Flow Interference Effects at Fracture Intersections, Water Resources Research, 12. pp. 102-104.

Witherspoon, P. A., J. S. Y. Wang, K. Iwa1, and J. E. Gale, 1980, Validity of Cubic Law for Fluid Flow in a Deformable Rock Fracture, Water Resources Research, 16, Pp. 1016-1024. 